Discussion Paper No. 14-116

\title{
Entry and Shakeout in Dynamic Oligopoly
}

Paul Hünermund, Philipp Schmidt-Dengler, and Yuya Takahashi

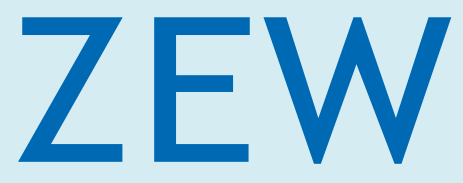

Zentrum für Europäische Wirtschaftsforschung $\mathrm{GmbH}$ Centre for European Economic Research 
Discussion Paper No. 14-116

\section{Entry and Shakeout in Dynamic Oligopoly}

\section{Paul Hünermund, Philipp Schmidt-Dengler, and Yuya Takahashi}

Download this ZEW Discussion Paper from our ftp server:

http://ftp.zew.de/pub/zew-docs/dp/dp14116.pdf

Die Discussion Papers dienen einer möglichst schnellen Verbreitung von neueren Forschungsarbeiten des ZEW. Die Beiträge liegen in alleiniger Verantwortung der Autoren und stellen nicht notwendigerweise die Meinung des ZEW dar.

Discussion Papers are intended to make results of ZEW research promptly available to other economists in order to encourage discussion and suggestions for revisions. The authors are solely responsible for the contents which do not necessarily represent the opinion of the ZEW. 


\title{
Entry and Shakeout in Dynamic Oligopoly*
}

\author{
Paul Hünermund ${ }^{\dagger} \quad$ Philipp Schmidt-Dengler ${ }^{\ddagger}$ \\ Yuya Takahashi ${ }^{\S}$
}

December 2014

In many industries, the number of firms evolves non-monotonically over time. A phase of rapid entry is followed by an industry shakeout: a large number of firms exit within a short period. We present a simple timing game of entry and exit with an exogenous technological process governing firm efficiency. We calibrate our model to data from the post World War II penicillin industry. The equilibrium dynamics of the calibrated model closely match the patterns observed in many industries. In particular, our model generates richer and more realistic dynamics than competitive models previously analyzed. The entry phase is characterized by preemption motives while the shakeout phase mimics a war of attrition. We show that dynamic strategic incentives accelerate early entry and trigger the shakeout by comparing a Markov Perfect Equilibrium to an Open-loop Equilibrium.

Key Words: Life Cycle, Dynamic Oligopoly, Preemption, War of Attrition, Penicillin

JEL Classification: L11, O

\footnotetext{
*We thank Luìs Cabral, Jeff Campbell, Michi Igami, Boyan Jovanovic, Glenn MacDonald, Konrad Stahl, Otto Toivanen, Andrew Toole, conference participants at ESEM 2013 in Gothenburg and EARIE 2014 in Milan, and seminar participants at University of Salzburg and San Francisco State University for helpful comments. We also thank Elizabeth Nesbitt at USITC for generously sharing data with us. Schmidt-Dengler and Takahashi gratefully acknowledge financial support from the German Science Foundation through SFB TR 15. All remaining errors are ours.

${ }^{\dagger} \mathrm{KU}$ Leuven and Centre for European Economic Research (ZEW), email: huenermund@zew.de

‡University of Vienna, also affiliated with CEPR, CES-Ifo, and ZEW, email: philipp.schmidtdengler@univie.ac.at

§Johns Hopkins University, email: ytakahashi@jhu.edu
} 


\section{Introduction}

Industries experiencing substantial growth in the number of firms in their early stage often undergo a rapid decline in the number of active firms -a shakeout- later on. Eventually the number of active firms settles at a level substantially below the observed peak. Utterback and Suarez (1993) and Suarez and Utterback (1995) document this pattern for several industries ranging from the typewriter industry, which originated in the late 19 th century, via automobiles, in the early 20th century, to television sets in the second half of the 20th century (see Figure 1). This life cycle pattern of growth and a subsequent drop in the number of firms is frequently coupled with increasing output and decreasing prices. ${ }^{1}$ Therefore this phenomenon cannot be explained by an exogenous decline in demand only.

To explain such an evolution of the number of firms, output, and prices, several papers in the literature study the role of firm heterogeneity in productivity or costs as a result of technological change. Most prominently, Jovanovic and MacDonald (1994) develop a competitive industry model where firms make dynamic entry and exit decisions and the industry's efficiency frontier is determined by a wave of aggregate exogenous innovations. The industry is created by a major innovation triggering the first wave of entry. A subsequent refinement of the innovation increases the efficient scale, but is challenging to adopt. Thus, only a fraction of firms can innovate successfully and increase the scale of production. ${ }^{2}$ Unless demand grows at a comparable speed, prices fall too quickly to sustain the existing number of firms, resulting in the exit of unsuccessful innovators.

While this competitive model describes a plausible mechanism behind shakeouts, i.e., successful cost reduction by only some firms and exit by remaining firms, it does not allow for firms' strategic interaction determining the life cycle pattern of industries. We argue that strategic interaction may play an important role, in particular in industries with a small number of firms. Consequently, we study a model with a finite number of firms, instead of a continuum of firms in a competitive environment as in Jovanovic and MacDonald (1994). We develop a simple dynamic oligopoly model similar in spirit to models by Ericson and Pakes (1995) and subsequent authors to highlight the importance of dynamic strategic interaction in shaping the evolution of an industry with a shakeout.

In our model, firms make entry and exit decisions every period. Entrants start with

\footnotetext{
${ }^{1}$ This pattern was observed in the U.S. automobile tire industry; see Jovanovic and MacDonald (1994). The post World War II penicillin industry also showed the same pattern, as we will discuss later.

${ }^{2}$ We thank Glenn MacDonald for pointing out to us that such scale economies tend to play a smaller role in service industries. The industries in Figure 1 all belong to the manufacturing sector.
} 
Figure 1: Examples of shakeouts in different industries

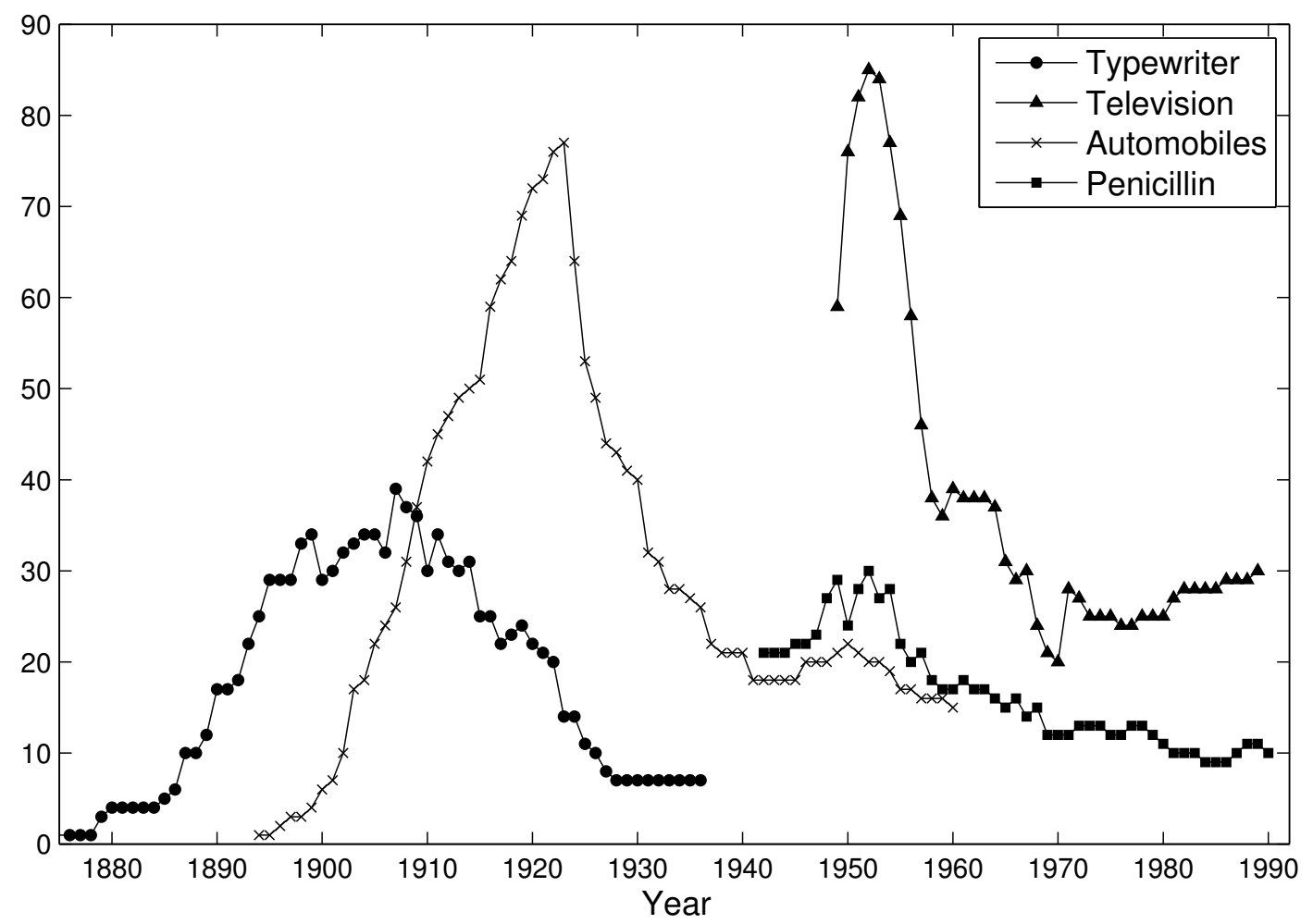

Notes: Number of active firms within the industries according to Utterback and Suarez (1993) and Klepper and Simons (2005, for penicillin).

the same level of efficiency. The individual efficiency of a continuing firm improves with exogenous probability. Since entry and exit are endogenous, the aggregate efficiency level in the industry evolves endogenously over time, in contrast to Jovanovic and MacDonald (1994). When sufficiently many firms have become efficient, unsuccessful firms exit the market by the same mechanism as in Jovanovic and MacDonald (1994). A Markov Perfect Equilibrium exists and generates an industry life cycle where the early phase is characterized by massive entry, followed by an industry shakeout once a few firms have successfully innovated. During the entry phase, firms have an incentive to enter the market early to increase their chance of becoming innovative and reduce competitors' incentives to enter. In the shakeout phase, however, firms want to outlast their competitors to secure profits. The dynamic game thus turns from a preemption race early on into a war of attrition when the number of firms has reached its peak.

We are not the first to emphasize the role of strategic incentives in entry decisions and industry evolution. Dixit and Shapiro (1986) and Cabral (1993) show that nonmonotone time paths in the number of firms can be the result of coordination failures 
arising in a mixed strategy equilibrium of a dynamic entry and exit game. This type of model can explain why some industries experience "overshooting" while others do not. An important difference is that the equilibrium market structure in our model is stochastic, while the model in Cabral (1993) predicts a deterministic market structure in the limit. In addition, our model is consistent with increasing output and decreasing prices over the entire life cycle, unlike these papers.

The literature on industry evolution has put forward several alternative mechanisms that are able to explain entry dynamics. Several authors stress the importance of information acquisition and learning. Horvath, Schivardi, and Woywode (2001) look at a strategic model with uncertainty regarding the profitability of an industry. Resolution of this uncertainty first drives entry and later exit. In Cabral (2011), firms have to choose one of several production technologies that initially look equally promising but only one proves to be superior over time. Sunk adoption costs let firms to invest in capacity levels that are lower than the long-term optimal level because of the fear to "back the wrong horse." Once the initial uncertainty is resolved, surviving incumbents make up leeway which triggers exit by others.

There are several other papers besides Jovanovic and MacDonald (1994) that use a competitive model to explain shakeouts. In Klepper (1996), firms make R\&D investment as well as entry and exit decisions taking only short run profits into account. The specific dynamics are generated by ex-ante heterogeneity in firms' innovative ability and firm specific demand inertia. Hopenhayn (1993) develops a model where firms differ according to their profitability. A selection of more profitable firms, due to their higher survival rates, leads to increasing average firm size over time. If the growth in firm size is larger than the growth rate of demand, a shakeout results.

Our approach provides a simple alternative model with several desirable features that complements the existing literature along three dimensions. First, the model has a stronger empirical nature as it generates aggregate uncertainty in market structure. Competitive models have been successful at generating general life cycle patterns of prices and quantities, but less successful at mimicking actual evolutions of producers in an industry. The competitive nature of the model by Jovanovic and MacDonald (1994) with a continuum of firms generates a rectangular shape for the evolution of number of firms, as entry and shakeout waves both occur within one period. In principle, our model could be estimated based on observations of entry and exit in the industry.

Second, in contrast to Jovanovic and MacDonald (1994) and Klepper (1996) our model involves strategic interaction. In particular, it allows for the identification of preemption 
motives in the entry phase and war of attrition motives in the shakeout phase. Firms in our model are forward looking and can manipulate the probability of becoming a technology leader with their entry and exit decisions. Thereby, our paper combines the ideas of firm heterogeneity and strategic incentives as the driving forces underlying a shakeout.

Third, we take calibrate our model to data from the post World War II penicillin industry. To do so, we estimate the demand for penicillin employing a novel instrument for price. We argue that the exogenous innovation process, the productivity enhancement caused by innovation, as well as sunk entry costs and scrap exit values can be identified by matching key features of the industry life cycle. Finally, we show that strategic interaction and forward looking behavior are important factors in determining the life cycle of the penicillin industry by quantifying strategic motives in the entry and exit decisions. Similarly to Igami and Yang (2014), using calibrated parameters, we compute a solution to an alternative model where firms pre-commit to a strategy depending only on their own state. By comparing entry probabilities given by this solution to entry probabilities implied by the Markov Perfect Equilibrium (MPE) of our model, we can isolate firm entry motivated by preemption incentives. We find that out of an entry probability of $42 \%$ in an MPE at the initial state, $6 \%$ can be attributed to preemption motives.

The remainder is organized as follows. Section 2 presents the dynamic model, characterizes the equilibrium, and illustrates how the model can generate a typical industry life cycle with entry and shakeout stages. Section 3 gives an overview of the penicillin industry and the data. It then presents the demand estimates and calibration results, and illustrates the role of the strategic interaction. Section 4 concludes.

\section{A dynamic model of entry and exit with process innovation}

\subsection{Setup}

This section describes the elements of the model, which is similar to models building on Ericson and Pakes (1995). Our exposition follows Pesendorfer and Schmidt-Dengler (2008). We consider a dynamic game of entry and exit with process innovation in discrete time, $t=1,2, \ldots, \infty$. The industry consists of up to $N$ firms. The set of firms is denoted by $\mathcal{N}=\{1, \ldots, N\}$ and a typical firm is denoted by $i \in \mathcal{N}$. Every period in time, firms 
choose whether to be active or not. ${ }^{3}$ In the following, we describe the sequencing of events, the period game, the transition function, the payoffs, the strategies, and the equilibrium concept.

Publicly observable state vector. Each firm is endowed with a firm-specific state variable $s_{i}^{t} \in \mathbf{S}_{i}=\left(\omega_{0}, \omega_{1}, \ldots, \omega_{K}\right)$. Let $s_{i}^{t}=\omega_{0}$ denote the state of a potential entrant, i.e., a firm not currently active in the market; $s_{i}^{t}=\omega_{k}$ for $k=1, \ldots, K$ denotes an active firm that has achieved efficiency level $k$. The vector of all firms' public state variables is denoted by $\mathbf{s}^{t}=\left(s_{1}^{t}, \ldots, s_{N}^{t}\right) \in \mathbf{S}=\times_{i=1}^{N} \mathbf{S}_{i}$. Sometimes we use the notation $\mathbf{s}_{-i}^{t}=\left(s_{1}^{t}, \ldots, s_{i-1}^{t}, s_{i+1}^{t}, \ldots, s_{N}^{t}\right) \in \mathbf{S}_{-i}$ to denote the vector of states by firms other than firm $i$. The cardinality of the state space $\mathbf{S}$ equals $m_{s}=(K+1)^{N}$.

Symmetric observable state space. We mostly restrict attention to situations in which the identity of other firms does not affect firm $i$ 's payoffs and decisions. We introduce the counting measure $\delta\left(\mathbf{s}_{-i}^{t}\right)$ which equals the $K$-dimensional vector, where each element contains the number of other firms in state $\omega_{k}$ for $k=1, \ldots, K$. The number of rival potential entrants (the number of rival firms in state $\omega_{0}$ ) is given by $N$ minus the sum of the elements of $\delta\left(\mathbf{s}_{-i}^{t}\right)$. A typical element of the "symmetric" state space is a $(K+1)$-dimensional vector $\left(s_{i}^{t}, \delta\right)$, which consists of firm $i$ 's state, and the number of rival firms in each state, $\delta\left(\mathbf{s}_{-i}^{t}\right)$. The cardinality of the symmetric state space equals $\left(\begin{array}{c}N+K-1 \\ K\end{array}\right) \cdot(K+1) \cdot{ }^{4}$

Privately observed payoff shocks. Each firm $i$ privately observes a two-dimensional payoff shock $\varepsilon_{i}^{t}=\left(\varepsilon_{i 0}^{t}, \varepsilon_{i 1}^{t}\right) \in \mathbb{R}^{2}$ that is drawn independently from a strictly monotone and continuous distribution function $F$. Independence of $\varepsilon_{i}^{t}$ from the state variables is an important assumption, since it allows us to adopt the Markov dynamic decision framework. $^{5}$ To ensure that the expected period return exists, we assume that $E\left[\varepsilon_{i \ell}^{t} \mid \varepsilon_{i \ell}^{t} \geq \varepsilon\right]$ exists for all $\varepsilon$ and $\ell=0,1$.

Actions. After observing the public state $\mathbf{s}^{t}$ and the private state variable $\varepsilon_{i}^{t}$, each firm decides whether to be active or not. We let $a_{i}^{t} \in \mathbf{A}_{i}=\{0,1\}$, where $a_{i}^{t}=0$ stands for a firm choosing to be inactive and $a_{i}^{t}=1$ stands for a firm choosing to be active. All $N$ firms make their decisions simultaneously. An action profile $\mathbf{a}^{t}$ denotes the vector of joint actions in period $t, \mathbf{a}^{t}=\left(a_{1}^{t}, \ldots, a_{N}^{t}\right) \in \mathbf{A}=\times_{i=1}^{N} \mathbf{A}_{i}$. The cardinality of the action space $\mathbf{A}$ is given by $2^{N}$. We sometimes use the notation $\mathbf{a}_{-i}^{t}=\left(a_{1}^{t}, \ldots, a_{i-1}^{t}, a_{i+1}^{t}, \ldots, a_{N}^{t}\right) \in \mathbf{A}_{-i}$

\footnotetext{
${ }^{3}$ While the total number of firms is fixed at $N$, the number of active firms endogenously changes over time. We could instead let the total number of firms change, but in such a case, we need to impose some assumption on the number of potential entrants; e.g., three new potential entrants make an entry decision every period.

${ }^{4}$ See Gowrisankaran (1999), also for an efficient representation of the state space in this case.

${ }^{5}$ For a discussion of the independence assumption in Markovian decision problems see Rust (1994).
} 
to denote the vector of actions undertaken by firms other than firm $i$.

Process innovation. There is an exogenous process that enhances active firms' capabilities. In particular, active firms in state $s_{i}^{t}=\omega_{k}$ with $k>0$ who choose to be active innovate with probability $\lambda_{k} \in(0,1)$.

State transitions. The state transition is described by a probability density function $g: \mathbf{A} \times \mathbf{S} \times \mathbf{S} \longrightarrow[0,1]$, where a typical element $g\left(\mathbf{a}^{t}, \mathbf{s}^{t}, \mathbf{s}^{t+1}\right)$ equals the probability that state $\mathbf{s}^{t+1}$ is reached when the current action profile and state are given by $\left(\mathbf{a}^{t}, \mathbf{s}^{t}\right)$. We require $\sum_{\mathbf{s}^{\prime} \in \mathbf{S}} g\left(\mathbf{a}, \mathbf{s}, \mathbf{s}^{\prime}\right)=1$ for all $(\mathbf{a}, \mathbf{s}) \in \mathbf{A} \times \mathbf{S}$. In our application, a firm's state $s_{i}^{t+1}$ depends on its current state $s_{i}^{t}$ and action $a_{i}^{t}$, as well as the outcome of the stochastic innovation process. The innovation process is governed by a vector of exogenous parameters $\Lambda=\left(\lambda_{1}, \ldots, \lambda_{K-1}\right)$ where each element of $\Lambda$ lies on the unit interval. In particular, if a firm is a potential entrant, i.e., $s_{i}^{t}=\omega_{0}$ we have

$$
s_{i}^{t+1}=\left\{\begin{array}{lll}
\omega_{0} & \text { w.p. } 1 & \text { if } a_{i}^{t}=0 \\
\omega_{1} & \text { w.p. } 1 & \text { if } a_{i}^{t}=1 .
\end{array}\right.
$$

For an incumbent, in state $\omega_{k}$ for $k=1, \ldots, K-1$ we have

$$
s_{i}^{t+1}=\left\{\begin{array}{lll}
\omega_{0} & \text { w.p. } 1 & \text { if } a_{i}^{t}=0 \\
\omega_{k} & \text { w.p. } 1-\lambda_{k} & \text { if } a_{i}^{t}=1 \\
\omega_{k+1} & \text { w.p. } \lambda_{k} & \text { if } a_{i}^{t}=1 .
\end{array}\right.
$$

Finally, for an incumbent, who has reached the maximum level of sophistication, i.e., $s_{i}^{t}=\omega_{K}$ we have

$$
s_{i}^{t+1}=\left\{\begin{array}{lll}
\omega_{0} & \text { w.p. } 1 & \text { if } a_{i}^{t}=0 \\
\omega_{K} & \text { w.p. } 1 & \text { if } a_{i}^{t}=1 .
\end{array}\right.
$$

Note that a firm's state transition is governed by the endogenous entry and exit decisions, $a_{i}^{t}$, as well as the exogenous innovation process described by the probability of innovation $\lambda_{k}$.

Period payoff. Payoff of firm $i$ is collected at the end of the period after all actions are observed. It consists of the action and state-dependent deterministic payoff and the private profitability shock. We can write period payoffs as a real-valued function defined on $\mathbf{S} \times \mathbf{A} \times \mathbb{R}$ and given by 


$$
\pi_{i}\left(a_{i}^{t}, \mathbf{a}_{-i}^{t}, s_{i}^{t}, \mathbf{s}_{-i}^{t}\right)+\sum_{\ell=0,1} \mathbf{1}\left(a_{i}^{t}=\ell\right) \varepsilon_{i \ell}^{t}
$$

The deterministic profit $\pi(\cdot)$ depends on four elements: (1) the choice of being active or not undertaken by the firm, $a_{i}^{t}$, (2) the firm's own state, $s_{i}^{t}$ (whether it has already been active and whether it has successfully innovated), (3) rival firms' decisions to be active or not, $\mathbf{a}_{-i}^{t}$, and (4) their states at the beginning of the period summarized by $\mathbf{s}_{-i}^{t}$. We assume that profits are bounded: $|\pi()|<.\infty$. In our application, $\pi($.$) is the$ sum of firm's profit earned in the period static game and one-time payoffs such as entry costs and scrap values.

Game payoff. Firms discount future payoffs with the common discount factor $\beta<1$. The game payoff of firm $i$ equals the sum of discounted period payoffs written as

$$
E\left\{\sum_{t=0}^{\infty} \beta^{t}\left[\pi\left(a_{i}^{t}, \mathbf{a}_{-i}^{t}, \mathbf{s}^{t}\right)+\sum_{\ell=0,1} \mathbf{1}\left(a_{i}^{t}=\ell\right) \varepsilon_{i \ell}^{t}\right] \mid \mathbf{s}^{0}, \varepsilon_{i}^{0}\right\},
$$

where the expectation is taken over future realizations of the state and payoff shocks.

Markovian strategies. Following Maskin and Tirole (1994, 2001), we consider pure Markovian strategies $a_{i}\left(\mathbf{s}^{t}, \varepsilon\right)$. A strategy for firm $i$ is a function of the publicly observable state variables and the firm specific profitability shock. The assumption that the profitability shock is independently distributed allows us to write the probability of observing action profile $\mathbf{a}^{t}$ as $\operatorname{Pr}\left(\mathbf{a}^{t} \mid \mathbf{s}^{t}\right)=\operatorname{Pr}\left(a_{1}^{t} \mid \mathbf{s}^{t}\right) \cdots \operatorname{Pr}\left(a_{N}^{t} \mid \mathbf{s}^{t}\right)$. The Markovian assumption then allows us to abstract from calendar time and subsequently we omit the time superscript.

Let $\sigma_{i}(\mathbf{a} \mid \mathbf{s})$ denote firm $i$ 's belief about the probability that action profile $\mathbf{a}$ is taken when the current state is s. Similarly, $\sigma_{i}\left(\mathbf{a}_{-i} \mid \mathbf{s}\right)$ denotes firm $i$ 's belief about the probability that its opponents take actions $\mathbf{a}_{-i}$ given $\mathbf{s}$. Using the beliefs, a firm's value function can be written as

$$
\begin{aligned}
W_{i}\left(\mathbf{s}, \varepsilon_{i} ; \sigma_{i}\right)=\max _{a_{i} \in \mathbf{A}_{i}}\left\{\sum_{\mathbf{a}_{-i} \in \mathbf{A}_{-i}} \sigma_{i}\left(\mathbf{a}_{-i} \mid \mathbf{s}\right)\right. & {\left[\pi\left(a_{i}, \mathbf{a}_{-i}, \mathbf{s}\right)+\sum_{\ell=0,1} \mathbf{1}\left(a_{i}=\ell\right) \varepsilon_{i \ell}\right.} \\
& \left.\left.+\beta \sum_{\mathbf{s}^{\prime} \in \mathbf{S}} g\left(\mathbf{s}^{\prime} \mid \mathbf{s}, a_{i}, \mathbf{a}_{-i}\right) \mathbb{E}_{\varepsilon} W_{i}\left(\mathbf{s}^{\prime}, \varepsilon_{i}^{\prime} ; \sigma_{i}\right)\right]\right\},
\end{aligned}
$$

where $g\left(\mathbf{s}^{\prime} \mid \mathbf{s}, a_{i}, \mathbf{a}_{-i}\right)$ denotes the probability that the industry reaches state $\mathbf{s}^{\prime}$ given 
current state profile $\mathbf{s}$ and actions $\left(a_{i}, \mathbf{a}_{-i}\right) . \mathbb{E}_{\varepsilon}$ denotes the expectation operator with respect to the firm specific payoff shock. The finiteness of the action and state space guarantees the existence of the value function $W_{i}$ in equation (2).

\subsection{Equilibrium}

We start by defining a Markov Perfect Equilibrium (MPE) in this game. An MPE is a pair of strategies and beliefs $(\mathbf{a}, \boldsymbol{\sigma})=\left(a_{1}, a_{2}, \ldots, a_{N}, \sigma_{1}, \sigma_{2}, \ldots, \sigma_{N}\right)$ that satisfies the following conditions. First, each firm's strategy $a_{i}$ is Markovian and a best response to $\mathbf{a}_{-i}$ given beliefs $\sigma_{i}$. Second, each firm's beliefs $\sigma_{i}$ are consistent with strategies $\mathbf{a}$.

Ex-ante Value Function. The firm's ex-ante value function $V_{i}(\cdot)$ describes its expected payoff in a given observable state before the privately observed profitability shock is realized and actions are taken: $V_{i}\left(\mathbf{s} ; \sigma_{i}\right)=\mathbb{E}_{\varepsilon} W_{i}\left(\mathbf{s}, \varepsilon_{i} ; \sigma_{i}\right)$. Given beliefs, we can write the firm's ex-ante value function as

$$
V_{i}\left(\mathbf{s} ; \sigma_{i}\right)=\sum_{\mathbf{a} \in \mathbf{A}} \sigma_{i}(\mathbf{a} \mid \mathbf{s})\left[\pi_{i}(\mathbf{a}, \mathbf{s})+\sum_{\ell=0,1} E\left(\varepsilon_{i \ell} \mid a_{i}=\ell\right)+\beta \sum_{\mathbf{s}^{\prime} \in \mathbf{S}} g\left(\mathbf{s}^{\prime} \mid \mathbf{s}, \mathbf{a}\right) V_{i}\left(\mathbf{s}^{\prime} ; \sigma_{i}\right)\right] .
$$

We now further exposit the optimal actions necessary to characterize and compute the equilibrium of our model. To do so, we define the choice-specific value

$$
v_{i}\left(a_{i}, \mathbf{s} ; \sigma_{i}\right)=\sum_{\mathbf{a}_{-i} \in \mathbf{A}_{-i}} \sigma_{i}\left(\mathbf{a}_{-i} \mid \mathbf{s}\right)\left[\pi_{i}\left(a_{i}, \mathbf{a}_{-i}, \mathbf{s}\right)+\beta \sum_{\mathbf{s}^{\prime} \in \mathbf{S}} g\left(\mathbf{s}^{\prime} \mid \mathbf{s}, a_{i}, \mathbf{a}_{-i}\right) V_{i}\left(\mathbf{s}^{\prime} ; \sigma_{i}\right)\right] .
$$

It is then optimal to choose action $a_{i}=1$ under beliefs $\sigma_{i}$ if and only if

$$
v_{i}\left(1, \mathbf{s} ; \sigma_{i}\right)+\varepsilon_{i 1} \geq v_{i}\left(0, \mathbf{s} ; \sigma_{i}\right)+\varepsilon_{i 0} .
$$

This characterizes the optimal decision rule up to a set of measure zero.

For this zero measure set we adopt, without loss of generality, that whenever equation (3) holds with equality, the firm chooses the higher action. The optimal policy $a_{i}$ satisfies

$$
a_{i}\left(\mathbf{s}, \varepsilon ; \sigma_{i}\right)=\underset{\ell \in\{0,1\}}{\operatorname{argmax}}\left\{v_{i}\left(\ell, \mathbf{s} ; \sigma_{i}\right)+\varepsilon_{i \ell}\right\} .
$$


The probability that firm $i$ chooses action $a_{i}=\ell$ is thus given by

$$
\begin{aligned}
p_{i}^{\ell}(\mathbf{s}) & =\psi_{i}\left(\ell, \mathbf{s} ; \sigma_{i}\right) \\
& =\operatorname{Pr}\left(v_{i}\left(\ell, \mathbf{s} ; \sigma_{i}\right)+\varepsilon_{i \ell} \geq v_{i}\left(j, \mathbf{s} ; \sigma_{i}\right)+\varepsilon_{i j}, j \neq \ell\right) .
\end{aligned}
$$

This relationship holds for all firms $i \in \mathcal{N}$ and states $\mathbf{s}$, and every action $\ell \in\{0,1\}$. This results in a system of $N \cdot m_{s}$ equations, which we can write compactly in vector notation as

$$
\mathbf{p}=\boldsymbol{\psi}(\boldsymbol{\sigma})
$$

where $\mathbf{p}$ denotes the $\left(N \cdot m_{s}\right)$-dimensional vector of choice probabilities and $\boldsymbol{\sigma}$ the $\left(N \cdot m_{s}\right)$ dimensional vector of beliefs.

In a Markov Perfect Equilibrium, beliefs $\boldsymbol{\sigma}$ correspond to choice probabilities $\mathbf{p}$ so that equation (5) becomes

$$
\mathbf{p}=\psi(\mathbf{p})
$$

It is immediate that any $\mathbf{p}$ satisfying (6) constitutes an equilibrium. Observe that this is a mapping from an $\left(N \cdot m_{s}\right)$-dimensional unit simplex into itself. Since the function $\boldsymbol{\psi}$ is continuous in $\mathbf{p}$, Brouwer's fixed point theorem applies and (6) has a solution in $\mathbf{p}$. Observe that the restriction to symmetric strategies under symmetric payoffs does not affect the argument.

Multiplicity. Multiplicity of equilibria is a well-known feature inherent to games. For the prevalence of multiple equilibria in the class of Markov games, see Doraszelski and Satterthwaite (2010) and Besanko, Doraszelski, Kryukov, and Satterthwaite (2010). Besanko, Doraszelski, Kryukov, and Satterthwaite (2010) provide sufficient conditions for uniqueness. If players' decisions are stagewise unique and movements in the state space are unidirectional, an equilibrium of the game is unique. The first condition, stagewise uniqueness, states that reaction functions given value functions cross only once at every stage of the game. This does not hold under a general continuous distribution of payoff shocks. The second condition is not satisfied either, as any current state may be reached again later in the game with a strictly positive probability.

\subsection{A numerical example}

We consider the simplest possible case to illustrate the model's ability to generate a typical industry life cycle with a shakeout. Assume that there are only three firm- 
specific states: potential entrant $\omega_{0}$, inefficient incumbent $\omega_{1}$, and efficient incumbent $\omega_{2}$. That is, $K=2$ and $s_{i} \in\left\{\omega_{0}, \omega_{1}, \omega_{2}\right\}$. If an inefficient incumbent decides to continue, it becomes efficient with probability $\lambda$. That is, it stays inefficient with probability $1-\lambda$. In each period, given the vector of firms' technological states, firms compete in the product market. We consider Cournot competition with constant-elasticity demand and asymmetric costs. ${ }^{6}$ The inverse demand is given by $P(Q)=\gamma Q^{-\eta}$ with $Q=\sum_{i} q_{i}$. Costs are given by

$$
C_{i}\left(q_{i}\right)= \begin{cases}c_{1} q_{i} & \text { if } s_{i}=\omega_{1} \\ c_{2} q_{i} & \text { if } s_{i}=\omega_{2} .\end{cases}
$$

We assume $0 \leq c_{2}<c_{1}<\gamma$. This feature models a setting where incumbents can reduce their costs and thereby increase their profits by successfully innovating.

Let $n_{k}(\mathbf{s})=\sum_{i \in \mathcal{N}} \mathbf{1}\left(s_{i}=\omega_{k}\right)$ denote the number of firms of type $k \in\{1,2\}$. In a symmetric Nash equilibrium, firms of the same type will produce the same quantity and earn the same profit. Let $q_{1}$ and $q_{2}$ denote the quantities produced by inefficient and efficient firms, respectively. Let also $\widetilde{\pi}_{1}$ and $\widetilde{\pi}_{2}$ be the corresponding profits.

In this model, whether both types of firms produce positive amounts in equilibrium depends on various market conditions. When $\eta c_{1}-n_{2}\left(c_{1}-c_{2}\right) \geq 0$, both types of firms produce positive amounts, and the equilibrium quantities of the static game are given by

$$
\begin{aligned}
& q_{1}^{*}(\mathbf{s})=\frac{\left[\frac{c_{1} n_{1}(\mathbf{s})+c_{2} n_{2}(\mathbf{s})}{\gamma\left(n_{1}(\mathbf{s})+n_{2}(\mathbf{s})\right)-\gamma \eta}\right]^{-\frac{1}{\eta}}}{\eta\left(c_{1} n_{1}(\mathbf{s})+c_{2} n_{2}(\mathbf{s})\right)}\left[\eta c_{1}+n_{2}(\mathbf{s})\left(c_{2}-c_{1}\right)\right], \\
& q_{2}^{*}(\mathbf{s})=\frac{\left[\frac{c_{1} n_{1}(\mathbf{s})+c_{2} n_{2}(\mathbf{s})}{\gamma\left(n_{1}(\mathbf{s})+n_{2}(\mathbf{s})\right)-\gamma \eta}\right]^{-\frac{1}{\eta}}}{\eta\left(c_{1} n_{1}(\mathbf{s})+c_{2} n_{2}(\mathbf{s})\right)}\left[\eta c_{2}+n_{1}(\mathbf{s})\left(c_{1}-c_{2}\right)\right] .
\end{aligned}
$$

Otherwise, they are given by

$$
\begin{aligned}
& q_{1}^{*}(\mathbf{s})=0 \\
& q_{2}^{*}(\mathbf{s})=\frac{1}{n_{2}(\mathbf{s})}\left[\frac{c_{2} n_{2}(\mathbf{s})}{\gamma n_{2}(\mathbf{s})-\gamma \eta}\right]^{-\frac{1}{\eta}} .
\end{aligned}
$$

In words, if the cost differential $\left(c_{1}-c_{2}\right)$ or the number of efficient firms is small, inefficient firms will produce positive quantities.

\footnotetext{
${ }^{6}$ We also use Cournot competition with linear demand and analyze industry shakeouts. The details of this specification are available upon request.
} 
The equilibrium price is calculated as

$$
P(\mathbf{s})=\frac{c_{1} n_{1}(\mathbf{s})+c_{2} n_{2}(\mathbf{s})}{n_{1}(\mathbf{s})+n_{2}(\mathbf{s})-\eta}
$$

The operating profits become

$$
\begin{aligned}
& \tilde{\pi}_{1}^{*}(\mathbf{s})=\left[P(\mathbf{s})-c_{1}\right] q_{1}^{*}(\mathbf{s}), \\
& \tilde{\pi}_{2}^{*}(\mathbf{s})=\left[P(\mathbf{s})-c_{2}\right] q_{2}^{*}(\mathbf{s}) .
\end{aligned}
$$

In addition, we assume active firms incur fixed costs $f$. If a firm is inactive, it earns zero profit. Moreover, if a firm was inactive in the previous period but chooses to be active this period, it incurs an entry cost $\xi$. Finally, if a firm was active in the previous period but chooses to be inactive this period, it collects a scrap value $\phi$.

Our model is sufficiently general to generate various types of evolution of the number of firms endogenously. We aim to generate an industry life cycle with the following three features: (1) a period of time with persistent entry, (2) a large fraction of firms exiting during a relatively short period of time, and (3) a period after the shakeout characterized by an oligopoly with a small number of incumbents and occasional entry and exits.

To replicate the first feature, the probability of successful process innovation should not be too high. With a low success probability, potential entrants keep entering the market even if there are already many incumbents. For the second feature, the profit of inefficient firms should decrease quickly as the number of efficient rivals increases in the market. A large cost differential $\left(c_{1}-c_{2}\right)$ can achieve the goal. Finally, demand should not be too high, so that only a small number of efficient firms can profitably operate in the market. In addition, the scrap value should be large enough compared to the period profit, so that even efficient incumbents occasionally exit after the market experienced a shakeout.

With these points taken into consideration, we parameterize the model as follows:

$$
\begin{aligned}
N & =25 \\
\lambda & =0.008 \\
(f, \xi, \phi) & =(0,200,30) \\
\left(c_{1}, c_{2}\right) & =(40,1) \\
(\gamma, \eta) & =\left(30, \frac{1}{2.5}\right) .
\end{aligned}
$$


Figure 2: Probability of being active

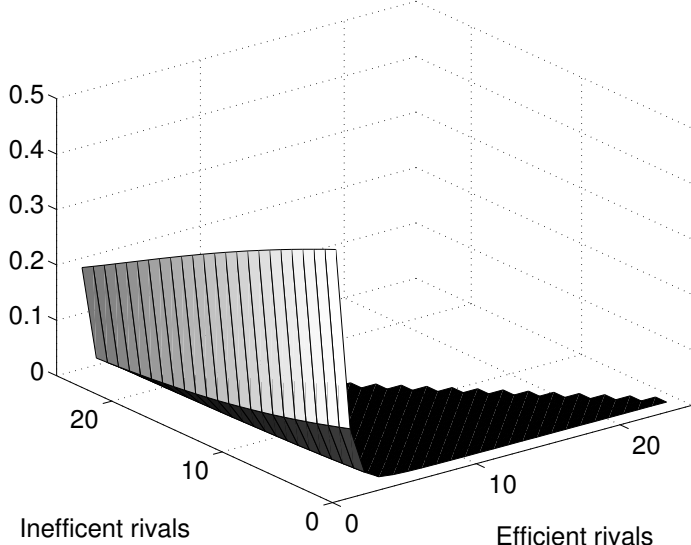

(a) For potential entrants

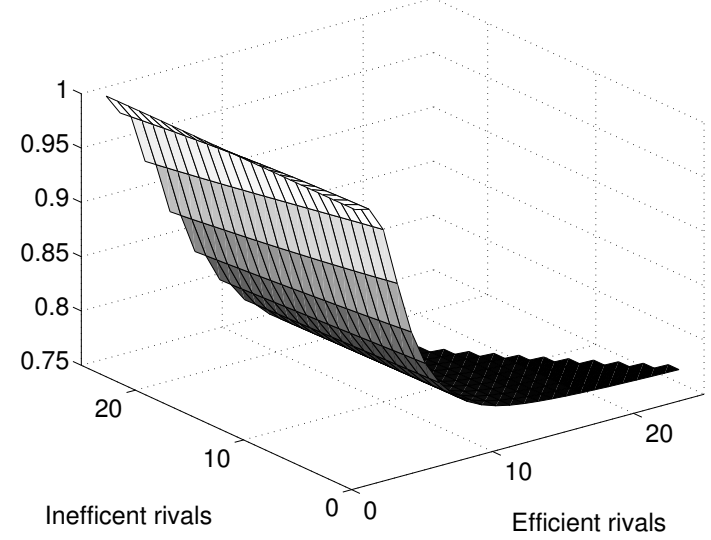

(b) For inefficient incumbents

Finally, we assume $\varepsilon$ follows the type-1 extreme value distribution with scaling parameter equal to 25. Note that the value of $\eta$ implies that the demand elasticity is 2.5.

In order to numerically solve for equilibria, the backward solution algorithm in Pakes and McGuire (1994) is used. For a vector of starting values, value functions and policy functions are updated in every iteration until the sequence of updated numbers converges to a previously specified criterion. Under these parameter values, we always find the same equilibrium regardless of where we start the solution algorithm. While this does not mean that the equilibrium is unique, in what follows we analyze the conditional choice probabilities and industry evolutions implied by this equilibrium.

Figure 2(a) plots the equilibrium probability of being active for potential entrants ("entry probability") for every pair of the number of efficient rivals and the number of inefficient rivals. It is clear that the entry probability is monotonically decreasing everywhere in both numbers of efficient and inefficient rivals. A noteworthy feature is that entry to the market almost ceases once the number of efficient rivals reaches three. On the contrary, firms still continue to enter even if there are many incumbents, as long as most of them are inefficient. Figure 2(b) shows the equilibrium probability of staying active for inefficient incumbents. With the small probability of innovation and the large cost differential, the preemption game is essentially over once two or three firms have successfully innovated. Note that inefficient incumbents do not necessarily leave the market even if the number of efficient rivals becomes large; i.e., their probability of being active converges to around 0.77 . This is because they have already incurred entry costs and therefore have an incentive to wait for their opponents to exit first or for a 
Figure 3: Numerical example, three simulated paths
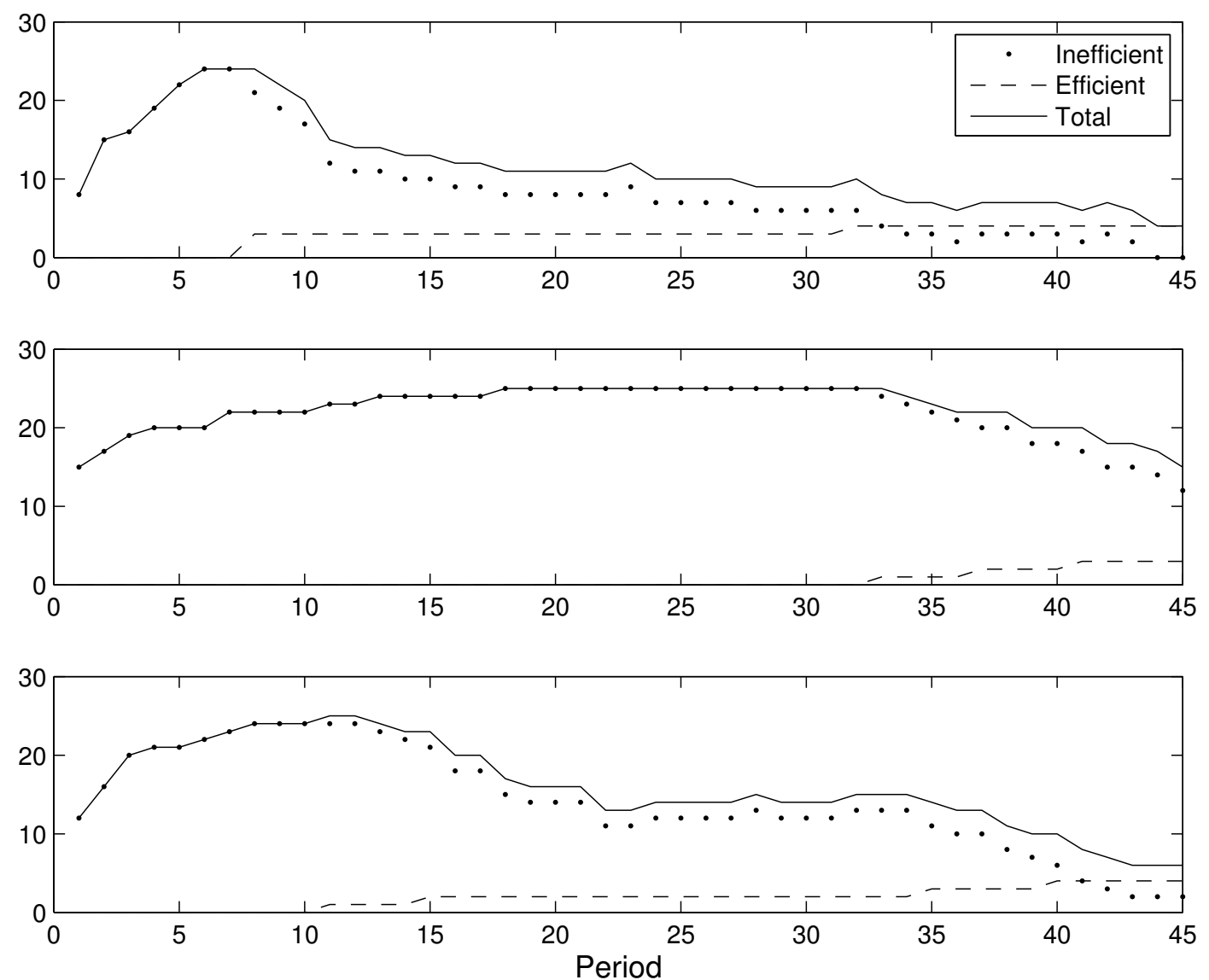

preferable draw of the scrap value.

Using these equilibrium probabilities, we simulate the model for a period of 45 years several times and plot the evolution of the number of inefficient, efficient, and total active firms. Figure 3 shows three such simulated paths and illustrates that the model can generate rich patterns of industry shakeouts. Overall, a successful promotion to being efficient triggers exits of other inefficient firms. Under the chosen parameter values, the industry becomes stable once four firms become efficient. Since promotions are stochastic, industry shakeouts show various patterns depending on when each promotion takes place. In the top panel of Figure 3, many firms enter the market early and three incumbents become efficient by period 8. Therefore, the shakeout is severe; afterwards, the industry gradually consolidates over time. The middle panel shows another extreme example. None of the inefficient firms become efficient for a long time, and therefore, there is persistent net entry for more than 20 periods. The bottom panel shows another simulated path where the first two promotions occur substantially earlier than the fol- 
Figure 4: Simulation averages
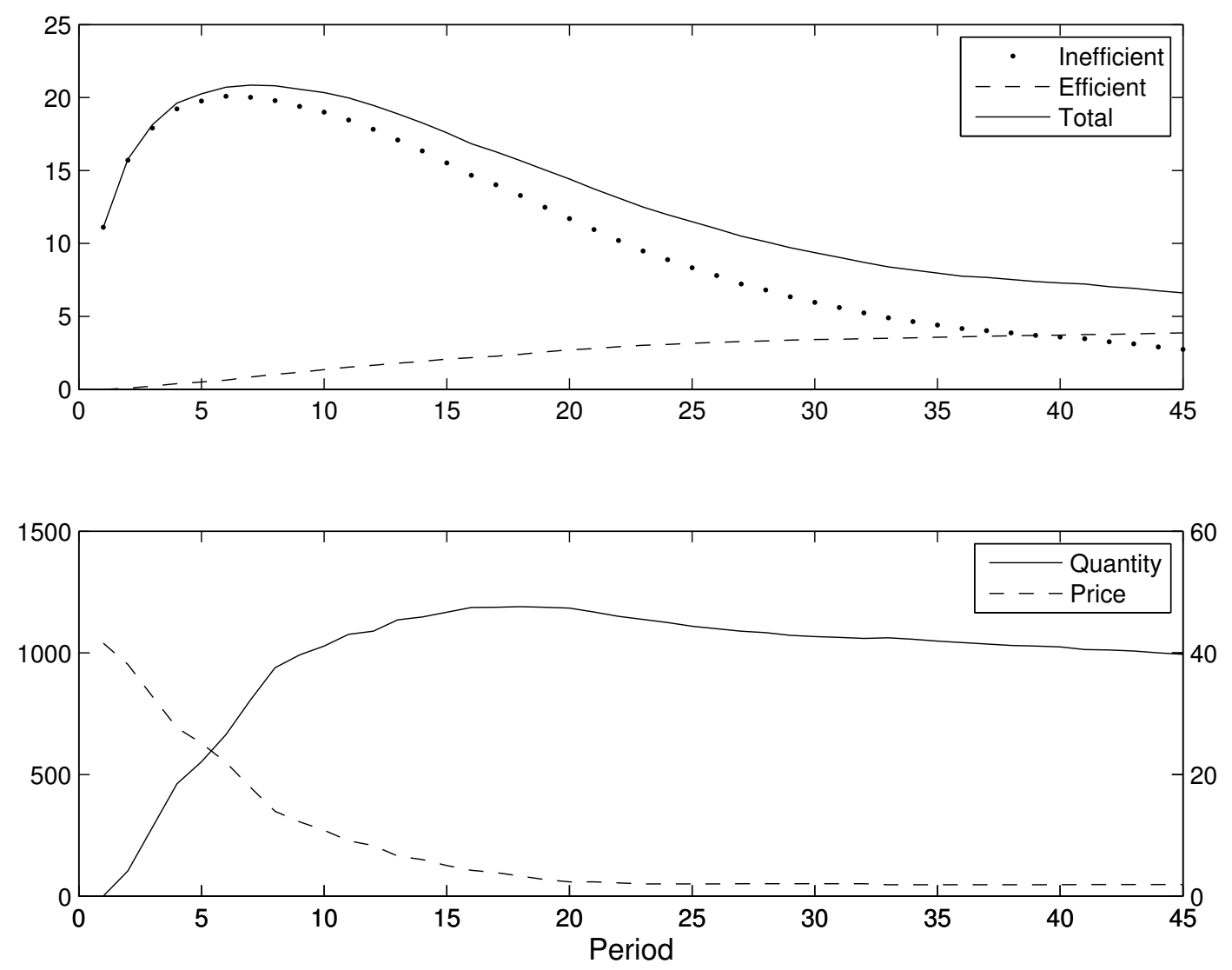

lowing two. Each promotion wave triggers an exit wave. This mimics, e.g., the evolution of the TV industry.

To see the average pattern, the top panel in Figure 4 depicts averages (over 200 simulated samples) of the number of inefficient firms, efficient firms, and the total number of active firms. We find the three features of industry evolution, which are mentioned above, to be replicated. The bottom panel plots averages of the equilibrium price and quantity over time. The model successfully replicates the basic pattern of decreasing price and increasing output over time (compare Figure 2 in Jovanovic and MacDonald, 1994, for the example of the U.S. tire industry). 


\section{Application: The U.S. penicillin industry}

\subsection{Industry background}

Penicillin, the first medically useful antibiotic drug effective against diseases such as bacterial infections, was discovered in 1928. Core of the penicillin production process is the fermentation of organic matter. Penicillium chrysogenum, a certain species of mold fungi, is grown in a nutrient medium, which then produces the desired antibiotic substance.

The development of production at industrial scale was promoted extensively by the U.S. government since the early 1940s. Research and development was funded at various places including the Department of Agriculture's Northern Regional Research Laboratory (NRRL), Stanford University and, the University of Wisconsin. During World War II, the War Production Board coordinated the joint efforts of development and effectively regulated entry into the wartime penicillin program due to considerations of national security or concerns about harmful competition within the new industry (Klepper and Simons, 1997, footnote 43). For example, large pharmaceutical companies such as Pfizer, Sqibb and Merck were involved in the development process, while a large amount of applications by other firms were denied.

By the end of WWII, several important industry standards for the penicillin production process and the utilized penicillin strains have been established. The methodology for submerged growth in large fermentation vessels was widely adopted for production on an industrial scale. In the early 1940s, a formerly used yeast extract was replaced by a growth medium that is based mainly on corn steep liquor, a byproduct of corn milling. This rich production broth realized a vast increase in production effectiveness (Neushul, 1993, p. 379) and soon became the industry standard (Tornqvist and Peterson, 1956).

These early advances in the fermentation process were followed by substantial efforts of selective breeding to discover higher-yielding penicillin strains. This process proved to be very successful (see the Appendix for a detailed history). As a result, the maximum penicillin yield rates increased at nearly exponential rates after 1945 (see Figure 5), which considerably reduced production costs. At the same time, entry restrictions were removed. Because of their strategic importance and the major public stakeholding, all early advances in penicillin production were licensed on a royalty-free basis and, in principle, available to entrants (Federal Trade Commission, FTC hereafter, 1958, p. 228-229). Thus, asymmetry in basic production technology between incumbents and new entrants was not substantial when the industry became unregulated (around 1946). 
Figure 5: Historical development of penicillin yields

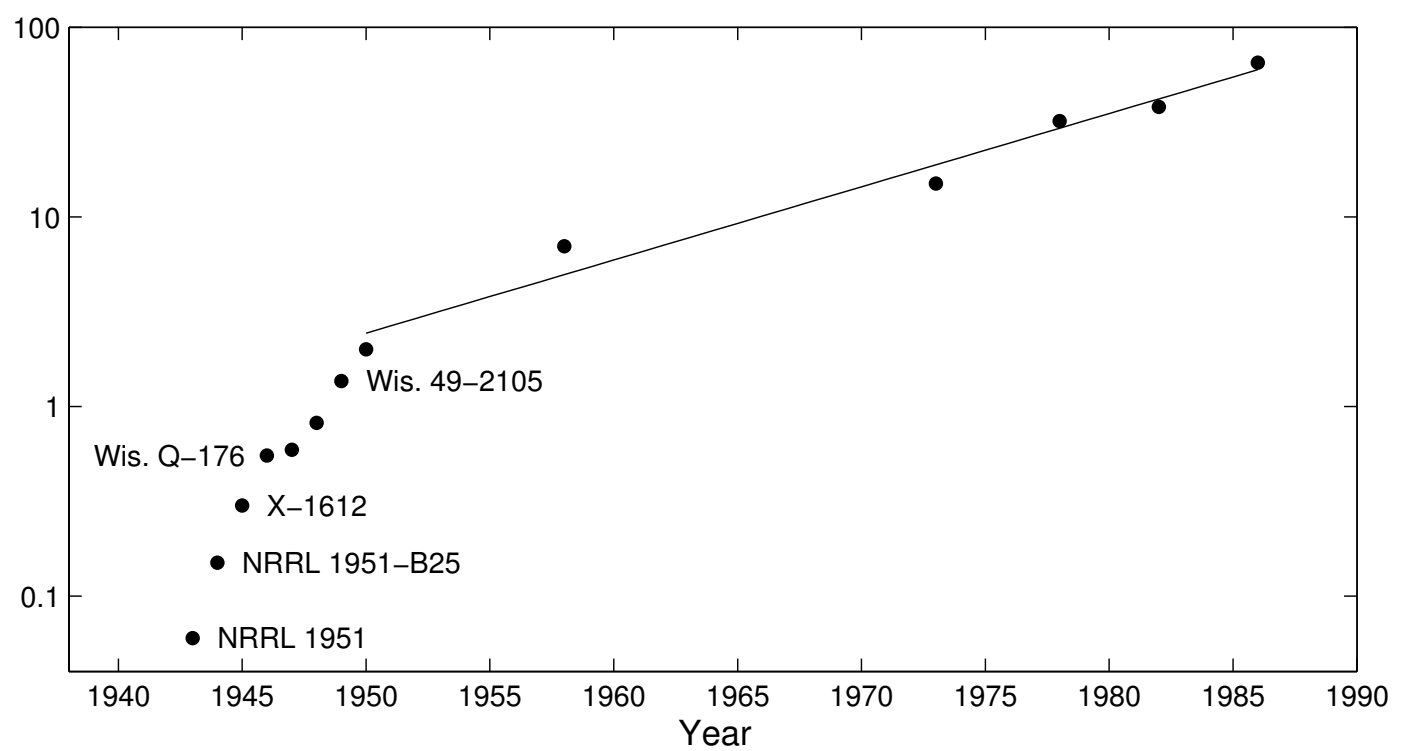

Notes: Maximum penicillin yield rates in gram per liter of production medium (loglinear scale). Various sources as described in the text. Regression line was fitted by a log-linear regression of yield rates on year for 1950 and later following Figure 10.1. in Calam (1987, p. 120). Data points for strain NRRL 1951, NRRL 1951-B25, and $X$-1612 (see Appendix) are not used for demand estimation in Section 3.2 and are reported for illustration only.

This is important to emphasize in our context, because every active firm including new entrants shares the basic production technology at the beginning of the game.

The number of producers soon increased from 21 in 1946 up to 30 in 1952. Figure 6 plots the time series of active firms, exits and entries from 1943 to 1992 based on Klepper and Simons (2005). After 1952, the penicillin industry experienced a shakeout with the number of active producers in the market decreasing by $70 \%$ until the early 1980s. Entry rates declined gradually over the industry evolution and exit rates peaked at the onset of the shakeout.

Mergers played a minor role in shaping the shakeout. Only $3 \%$ of the exits after the peak and $0 \%$ before were related to acquisitions (Klepper and Simons, 2005, p. 27). Furthermore, acquisitions by firms outside of the industry were recorded as continuations of the acquired firm (p. 25). It is also important to note that the few remaining firms increased output constantly until the mid 1970s, and thus the shakeout was not due to a decline in demand (see Figure 7).

Although information on the early advances in penicillin production technology was spread actively, adopting those technologies and operating at the current industry tech- 
Figure 6: The shakeout in the U.S. penicillin industry

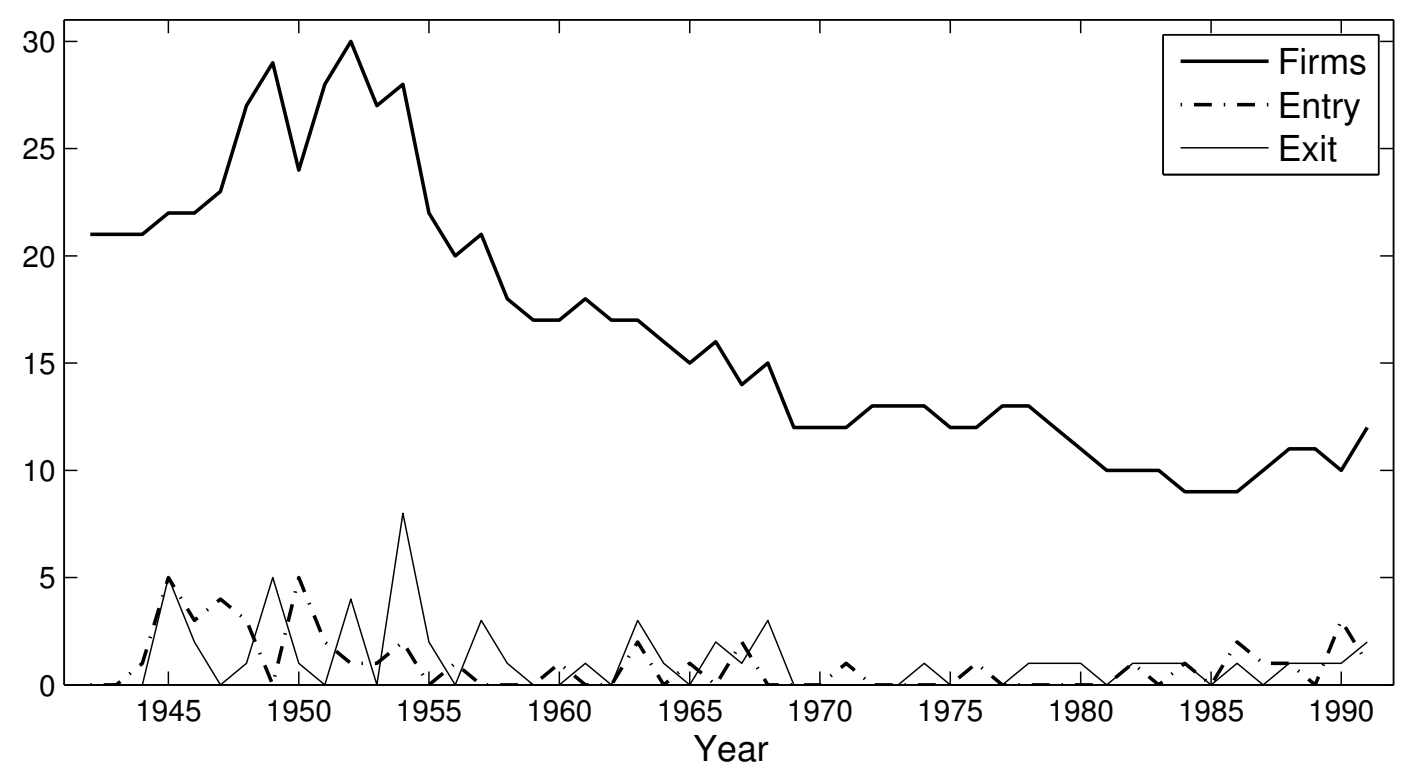

Notes: Number of firms producing penicillin products. Data collected from Figure 1 in Klepper and Simons (2005).

nology frontier were, in general, not trivial. A report by the FTC describes that all manufacturers in the industry had prior experience in the pharmaceutical industry. They had to invest large amounts into their production plants and rapid technological advances commonly outmoded existing plants (FTC, 1958, p. 102-105). Firms surviving the shakeout were, for the predominant part, the largest and earliest producers in the industry (p. 82). This observation is consistent with our model in which efficient firms have higher production capabilities and earlier producers are more likely to be efficient.

In our model, the non-trivial nature of technology adoption is captured by the randomness in process innovation. While we do not treat innovation efforts (e.g., R\&D) as an explicit endogenous variable, we allow firms to increase the probability of becoming more efficient over time by staying active and producing. We believe that this simple process of innovation provides a good approximation to the situation where every firm has potential to operate at the industry technology frontier and tries to keep up with the frontier.

Product innovations were not common in the early penicillin industry. Until the late 1950s, there was only one major product innovation (Klepper and Simons, 1997). The acid-resistant penicillin $\mathrm{V}$ survives in the intestinal tract and can be given orally compared to the previously used injection of benzylpenicillin (penicillin G). Despite an additional precursor for fermentation, the production process is similar. This new form 
Figure 7: Historical sales and prices for penicillin

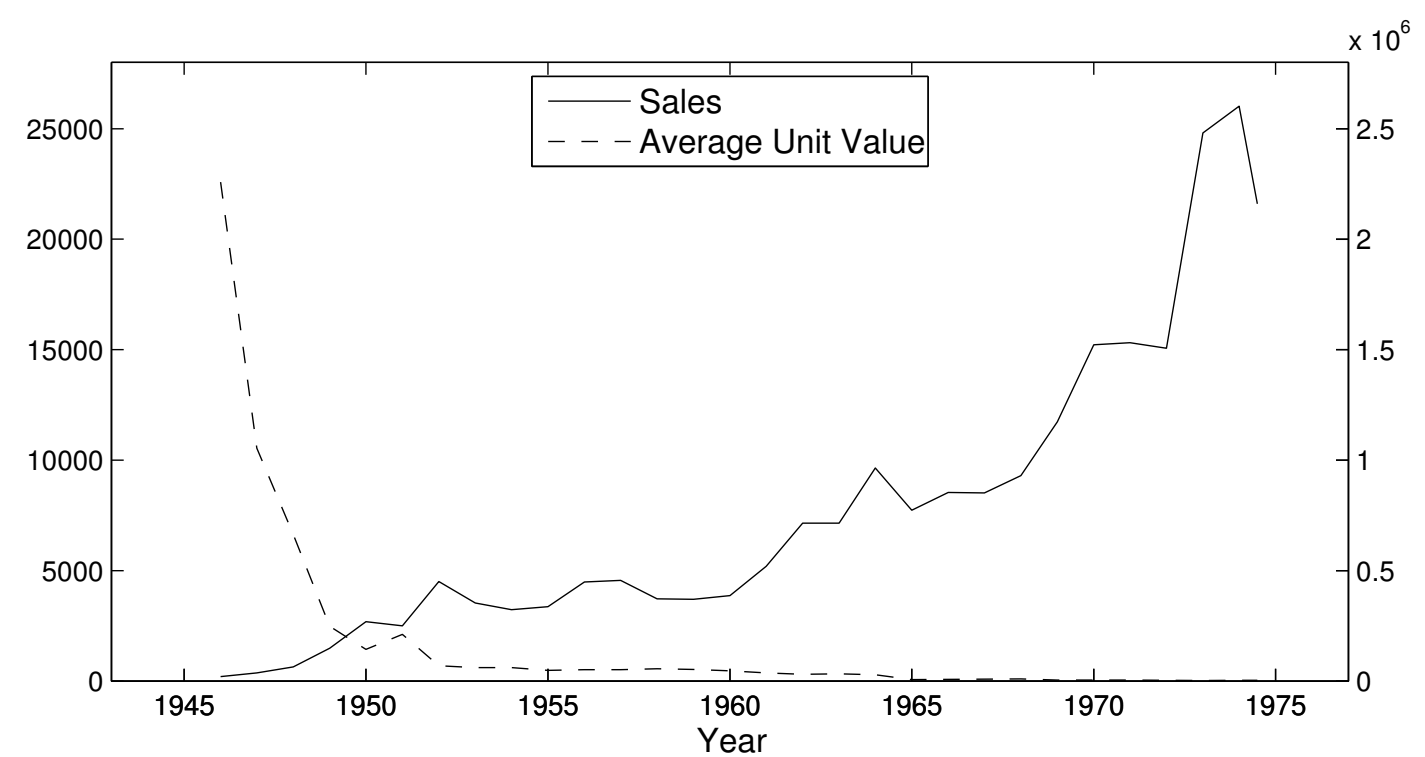

Notes: Average unit values in 1982 USD. Sales in billion international units. Data collected from SOC reports, various years.

of penicillin was introduced commercially in 1955, and is thus unlikely to be the main driving force of a shakeout that had begun three years before. Moreover, sales of previous penicillin forms remained high and could even be increased (Klepper and Simons, 1997, Table 15 and 16).

Another product innovation, the development of new semisynthetic forms of penicillin, started in 1958. It became possible to manipulate the side-chain of the penicillin nucleus, 6-aminopenicillanic acid. Since these novel forms of penicillin addressed different kind of diseases, this innovation rather opened new sub-markets of antibiotics than competing directly with the previously available forms of penicillin (Klepper and Simons, 1997, p. 433). ${ }^{7}$

\subsection{Demand estimation}

We obtain yearly data on sales and unit values for 1946 to $1984^{8}$ from the Synthetic Organic Chemicals (SOC) reports published by the United States Tariff Commission.

\footnotetext{
${ }^{7}$ In addition, the total chemical synthesis of penicillin eventually became possible in 1959. However, it never proved to be economically efficient (Neushul, 1993, p. 384).

${ }^{8}$ Data for 1980 are missing since the respective report was not available on USTC's website (November 2013). We restrict attention to reported figures that exclude semisynthetic types of penicillin. For years later than 1984 separate figures for non-semisynthetic penicillin were not reported.
} 
Sales were denoted in billion international units ${ }^{9}$ (IU). We calculate average unit prices from SOC's aggregate figures and deflate the series to 1982 dollars. Figure 7 shows sales and price movements. Prices fell sharply in the early years of the industry. In 1946, when penicillin was first introduced to the open market (Barreiro, Martin, and GarciaEstrada, 2012), price was $\$ 22,580$ per billion IU on average, which dropped to $\$ 520$ in 1956. Sales increased until 1974 from where they showed a volatile downward trend.

We employ a log-linear demand specification with a constant elasticity of demand and control for national income and a time trend. As instruments for the endogenous price, we have three variables at hand. First, we obtain average hourly earnings of production and nonsupervisory employees in manufacturing from Federal Reserve's Economic Data. ${ }^{10}$ This serves as a measure for the input price of labor. Unfortunately, the corresponding separate time series for the pharmaceutical industry was not available.

Second, as previously mentioned, corn steep liquor was an important input factor in the penicillin fermentation. From the Feed Grains Database, provided by United States Department of Agriculture ${ }^{11}$, we extract data on the weighted-average farm price of corn which serves as a supply shifter.

Third, we make use of maximum attainable yield rates of penicillin per amount of production medium. The growth in yield rates was one of the most important determinants of a reduction in manufacturer's costs. Thus, penicillin yield can be used as a valid instrument if it is not related to unobservable demand shocks. In general, investments in $\mathrm{R} \& \mathrm{D}$ are not independent of demand shocks. However, we argue that in the case of penicillin the innovation outcome can be regarded as exogenous due to the substantial involvement of the public sector, which allocates development resources based on long-term needs for military and government. In addition, the type of basic research responsible for the enormous advances in penicillin yields is arguably determined by the overall advancement of science, not by unobserved shocks of penicillin demand.

We collect data on the yield rates of different penicillin strains. With the maximum yield rates for a given year, attained by the strains available at that time, we construct a measure of the industry's extensive margin of production. Because of the high public and scientific interest, innovations in penicillin are well documented until the 1950s (see

\footnotetext{
${ }^{9}$ Older publications use the term Oxford Unit which is a measure for the biological activity of a substance. The Oxford Unit specific to penicillin $\mathrm{G}$ was defined to be the international unit and exhibits a conversion factor of 1,670 IU per mg (Humphrey, Mussett, and Perry, 1952). Penicillin V possesses the same conversion ratio (Federal Trade Commission, 1958, p. 355). Klepper and Simons (1997) state that an amount of 500,000 IU per day were necessary to treat a severe medical case.

${ }^{10}$ See: http://research.stlouisfed.org/fred2 (November 2013).

${ }^{11}$ See: www.ers.usda.gov/data-products/feed-grains-database (September 2013).
} 
Table 1: Penicillin demand estimates

\begin{tabular}{|c|c|c|c|c|c|}
\hline & (1) & $(2)$ & (3) & (4) & $(5)$ \\
\hline $\ln$ (Price) & $\begin{array}{c}-1.469^{* * *} \\
(0.379)\end{array}$ & $\begin{array}{c}-1.480^{* * *} \\
(0.391)\end{array}$ & $\begin{array}{c}-1.429^{* * *} \\
(0.350)\end{array}$ & $\begin{array}{c}-1.075^{* * *} \\
(0.062)\end{array}$ & $\begin{array}{c}-1.079^{* * *} \\
(0.034)\end{array}$ \\
\hline $\ln (\mathrm{GDP})$ & $\begin{array}{l}-1.563 \\
(1.939)\end{array}$ & $\begin{array}{l}-1.614 \\
(1.989)\end{array}$ & $\begin{array}{l}-1.377 \\
(1.794)\end{array}$ & $\begin{array}{c}0.287 \\
(0.998)\end{array}$ & $\begin{array}{c}0.268 \\
(0.879)\end{array}$ \\
\hline Year & $\begin{array}{c}-0.103^{* * *} \\
(0.029)\end{array}$ & $\begin{array}{c}-0.103^{* * *} \\
(0.029)\end{array}$ & $\begin{array}{c}-0.103^{* * *} \\
(0.029)\end{array}$ & $\begin{array}{c}-0.103^{* * *} \\
(0.030)\end{array}$ & $\begin{array}{c}-0.103^{* * *} \\
(0.030)\end{array}$ \\
\hline Constant & $\begin{array}{c}235.421^{* * *} \\
(53.697)\end{array}$ & $\begin{array}{c}235.860^{* * *} \\
(53.792)\end{array}$ & $\begin{array}{c}233.836^{* * * *} \\
(53.938)\end{array}$ & $\begin{array}{c}219.610^{* * *} \\
(52.244)\end{array}$ & $\begin{array}{c}219.769^{* * *} \\
(52.968)\end{array}$ \\
\hline$N$ & 38 & 38 & 38 & 38 & 38 \\
\hline$R^{2}$ & 0.807 & 0.804 & 0.817 & 0.878 & 0.878 \\
\hline \multicolumn{6}{|l|}{ First Stage: } \\
\hline$F$ & 5.003 & 2.691 & 14.147 & 6.844 & 200.3 \\
\hline$\chi^{2}$ (p-val.) & - & 0.120 & 0.229 & 0.156 & 0.187 \\
\hline \multicolumn{6}{|c|}{$\begin{array}{l}*(p<0.1), * *(p<0.05),{ }^{* * *}(p<0.01) \\
\text { Instruments: }(1) \text { hourly wage in manufacturing, }(2) \text { hourly wage and average farm-price of } \\
\text { corn, }(3) \text { to }(5) \text { manufacturing wage and yield of penicillin per liter of production medium. } \\
\text { In }(3) \text { years between innovative breakthroughs in yield are approximated by a step function, } \\
\text { in }(4) \text { we use linear interpolation, and in }(5) \text { a log-linear approximation. } \\
\text { Heteroskedasticity- and autocorrelation-robust standard errors in parantheses. Estimates } \\
\text { were obtained via 2SLS. The table reports F-statistics for the joint significance of the exoge- } \\
\text { nous variables in the first-stage regression. The } \chi^{2} \text { test of the overidentifying restrictions } \\
\text { is based on Wooldridge }(1995) \text {. }\end{array}$} \\
\hline
\end{tabular}

Appendix). For the years 1950 and later we consult Calam (1987). Since this time series is not complete we apply different methods of imputation. The first consists of constant interpolation, resulting in a step-function. Secondly, we interpolate linearly. As a last method, given the nearly exponential growth in yield rates, we use log-linear parametric interpolation (see Figure 5).

Table 1 reports two-stage least squares estimation results. Column (1) represents estimation with manufacturing wage being the sole instrument. Column (2) shows estimation with wage and corn price employed as instruments. A decline in the first-stage F-statistic indicates that corn price constitutes a rather weak instrument. It is thus omitted from the subsequent specifications. Columns (3) to (5) depict estimation with manufacturing wage and yield as instruments, with varying imputation methods for yield in gram per liter as described above. The estimated elasticity of demand shows a slight decrease for the finer imputation methods in (4) and (5). They, however, bear a 
potential collinearity problem given the included exponential time trend and the exponential growth of yield rates. A test of overindentifying restrictions is conducted to lend credibility to our exogeneity assumption and we give preference to specifications with higher first-stage F-statistics to avoid the problem of weak instruments.

\subsection{Calibration}

We calibrate the simplified model that we analyze in Section 2.3. Using the "staticdynamic" breakdown, we fix the demand parameters and calibrate other parameters by matching the predictions of the model with their empirical counterparts. We use the demand elasticity in specification (3) of Table 1, which balances sufficiently strong instruments with fewer concerns about collinearity due to the employed imputation method.

In order to identify the parameters, we need the following normalizations. First, recall that

$$
Q=n_{1} q_{1}+n_{2} q_{2}, \text { and } P=\frac{c_{1} n_{1}+c_{2} n_{2}}{n_{1}+n_{2}-\eta}
$$

Using the optimal solution in (7) and (8), $q_{1}$ and $q_{2}$ are implied by $\left(c_{1}, c_{2}, n_{1}, n_{2}\right)$. Thus, with data on the aggregate quantity and price $(Q$ and $P)$, this is a system of two equations with four unknowns. Knowing $\left(n_{1}, n_{2}\right)$, the two equations above pin down $c_{1}$ and $c_{2}$. However, only the sum of $n_{1}$ and $n_{2}$ is observed in the data. Therefore, we can at most identify $c_{1}$ relative to $c_{2}$ (or vice versa). Second, given that the price is a measurefree index and that profits are not observed, we can freely choose the demand parameter $\gamma$. Third, since it is not feasible to separately identify the entry cost, scrap value, and the fixed cost based solely on entry and exit data, we normalize $f=0$. Finally, we set the potential number of firms to 30 . To summarize:

$$
\begin{aligned}
N & =30 \\
f & =0 \\
c_{2} & =1 \\
(\gamma, \eta) & =\left(250, \frac{1}{1.429}\right) .
\end{aligned}
$$

The set of calibrated parameters includes the promotion probability $\lambda$, the marginal cost of inefficient firms $c_{1}$, the entry cost $\xi$, and the scrap value $\phi$. To capture important 
Table 2: Calibrated parameters

\begin{tabular}{ccr}
\hline & Parameter & Calibrated Value \\
\hline$\lambda:$ & Promotion probability & 0.0035 \\
$\xi:$ & Entry cost & 133.762 \\
$\phi:$ & Scrap value & 21.018 \\
$c_{1}:$ & MC of inefficient firms & 45.191 \\
\hline
\end{tabular}

features of industry shakeouts, we include the following six moments: (1) the average number of active firms, (2) the maximum number of firms, (3) time until the number of firms reaches the maximum, (4) the minimum number of active firms after the peak, (5) the total number of entry, and (6) the total number of exits. The first four moments jointly pin down the location and shape of the inverse- $U$ path of the number of active firms. The firm turnover, given by the fifth and sixth moments, mainly pins down the entry cost and scrap value.

We make use of the data from 1946 to 1991 to calculate the empirical moments. To obtain moments implied by the model, for any parameter values, we compute an equilibrium and take averages over 200 simulated sample paths over 46 time periods. ${ }^{12}$ The objective function is defined as the sum of the percentage deviation between the data and model moments. Table 2 reports the calibrated parameters. One striking result is that the marginal cost of inefficient firms is very high compared to that of efficient firms (approximately 45 times as high). Although this appears to be unrealistic from the viewpoint of our application, the result may not be too surprising since we aim to replicate a complicated industry pattern by a simple innovation process with only two technology levels. To understand the magnitude of the calibrated promotion probability, suppose 25 inefficient firms stay in the market from $t=0$. The probability that at least one of these inefficient firms becomes efficient by the end of the third, sixth, and nineth time period is $23 \%, 41 \%$, and $55 \%$, respectively. Finally, Table 3 shows that the model is able to match the empirical moments very well.

\subsection{Strategic incentives}

Our dynamic oligopoly model departs from the existing literature on the industry life cycle by explicitly allowing for strategic interaction. In this subsection, we illustrate the

\footnotetext{
${ }^{12}$ As before, there may be multiple equilibria. We always start the solution algorithm from $V_{i}\left(\mathbf{s} ; \sigma_{i}\right)=$ $\frac{\pi(\mathbf{s})}{1-\beta}$ and $p_{i}^{1}(\mathbf{s})=0.1$ for all $\mathbf{s}$, and use the equilibrium that we find first.
} 
Table 3: Empirical and calibrated moments

\begin{tabular}{crr}
\hline Moment & Data & Model \\
\hline Average $n$ & 15.98 & 17.61 \\
Maximum $n$ & 30.00 & 28.84 \\
Time until $n$ reaches maximum & 6.00 & 6.03 \\
Minimum $n$ after the peak & 9.00 & 8.88 \\
Number of entry & 40.00 & 40.20 \\
Number of exit & 51.00 & 50.90 \\
\hline
\end{tabular}

role strategic incentives play in firms' entry and exit decisions. We focus on two types of incentives. The life cycle pattern of an industry like the penicillin industry suggests that the game starts in a preemption phase early on and subsequently turns into a war of attrition phase. We quantify strategic incentives for these two phases using calibrated parameters.

Preemption incentive. Firms want to enter early and thereby reduce rival firms' incentives to enter. This is offset by a desire of firms to wait for a favorable entry cost draw. We quantify the preemption incentive by comparing the expected number of competitors an individual firm faces in the next period depending on its own state, $e\left(s_{i}, \mathbf{s}_{-i}\right)$. Since we are focusing on symmetric strategies, $\mathbf{s}_{-i}$ can be summarized by the number of inefficient and efficient rival incumbents, $n_{1}^{r}$ and $n_{2}^{r}$. We examine how a firm can affect the number of rival competitors with its entry by comparing the expected number of competitors a firm faces when it is either inactive $\left(s_{i}=0\right)$ or when it is an inefficient incumbent $\left(s_{i}=1\right)$,

$$
e\left(0, n_{1}^{r}, n_{2}^{r}\right)-e\left(1, n_{1}^{r}, n_{2}^{r}\right)
$$

To illustrate the effect further, we also compute the effect of entry on a firm's ex-ante value function with reversed signs, $V\left(1, n_{1}^{r}, n_{2}^{r}\right)-V\left(0, n_{1}^{r}, n_{2}^{r}\right)$.

War of attrition incentive. Firms want to outlast their rivals since it increases their own probability of survival. Once a sufficient number of rival firms have innovated, the returns to becoming a successful innovator are small. Firms thus have an increasing incentive to outlast their rivals and obtain one of the remaining "slots" among profitable successful innovators. To quantify this, we compute the effect of an inefficient incumbent outlasting one inefficient rival on the expected number of rival firms,

$$
e\left(1, n_{1}^{r}, n_{2}^{r}\right)-e\left(1, n_{1}^{r}-1, n_{2}^{r}\right)
$$


Similarly, we document the effect by looking at differences in ex-ante value functions, $V\left(1, n_{1}^{r}, n_{2}^{r}\right)-V\left(1, n_{1}^{r}-1, n_{2}^{r}\right)$.

Figure 8 depicts the preemption incentive. The left panel for the expected number of firms and the right panel for value functions paint a very similar picture: a strong preemption incentive at the beginning of the game when no or few firms have entered. The incentive is largely unaffected by the number of inefficient rival incumbents, but declines very quickly as the first firms innovate successfully.

Figure 9 shows the war of attrition incentive. Again, the left panel illustrates the incentive for the expected number of firms and the right panel for value functions. A slightly different picture emerges. The effect is barely present when no firm has yet successfully innovated and attains its peak when around two firms have successfully innovated. This corresponds to the point where the preemption incentive has become negligible and confirms our hypothesis about a gradual transition in the relative importance of the two strategic incentives present in the game.

To further investigate the impact of strategic interaction on the industry evolution, we define and compute an "Open-loop" Equilibrium (OLE) where each player is not allowed to condition its strategy on rivals' states. The firms pre-commit to a strategy depending only on their own state. Pre-commitment rules out preemptive motives (Fudenberg and Tirole, 1985) and strategic delay by assumption. Let $\bar{\varepsilon}_{i}^{s_{i}}$ be the threshold level of $\varepsilon_{i 1}-\varepsilon_{i 0}$ such that player $i$ is indifferent between choosing to be active and choosing not to be active when its own state is $s_{i} \in\{0,1,2\}$. The optimal strategy profile in MPEs can be represented in terms of such threshold payoff shocks (Pesendorfer and SchmidtDengler, 2008). We use the same representation, but the difference here is that player $i$ 's decision can be based only on $s_{i}$, instead of $\left(s_{i}, \delta\right)$. The decision rule is thus given by $a_{i}^{t}\left(\varepsilon_{i}, s_{i} ; \bar{\varepsilon}_{i}^{s_{i}}\right)=\mathbf{1}\left(\varepsilon_{i 1}-\varepsilon_{i 0} \geq \bar{\varepsilon}_{i}^{s_{i}}\right)$. In words, this may be thought of as a game where each player simultanously chooses a triple $\left(\bar{\varepsilon}_{i}^{0}, \bar{\varepsilon}_{i}^{1}, \bar{\varepsilon}_{i}^{2}\right)$ at $t=0$.

The game payoff of firm $i$ (before $\varepsilon_{i}^{0}$ is observed) is

$$
\begin{aligned}
& U_{i}\left(\bar{\varepsilon}_{i}^{0}, \bar{\varepsilon}_{i}^{1}, \bar{\varepsilon}_{i}^{2} ; \bar{\varepsilon}_{-i}^{0}, \bar{\varepsilon}_{-i}^{1}, \bar{\varepsilon}_{-i}^{2}, \mathbf{s}^{0}\right) \\
= & E\left\{\sum_{t=0}^{\infty} \beta^{t}\left[\pi\left(a_{i}^{t}\left(\varepsilon_{i}, s_{i} ; \bar{\varepsilon}_{i}^{s_{i}}\right), \mathbf{a}_{-i}^{t}, s_{i}^{t}, \delta^{t}\right)+\sum_{\ell=0,1} \mathbf{1}\left(a_{i}^{t}\left(\varepsilon_{i}, s_{i} ; \bar{\varepsilon}_{i}^{s_{i}}\right)=\ell\right) \varepsilon_{i \ell}^{t}\right] \mid \mathbf{s}^{0}\right\}
\end{aligned}
$$

where $\mathbf{a}_{-i}^{t}$ depends on $\left(\bar{\varepsilon}_{-i}^{0}, \bar{\varepsilon}_{-i}^{1}, \bar{\varepsilon}_{-i}^{2}\right)$ and the realization of payoff shocks. The OLE is a strategy profile $\left\{\left(\bar{\varepsilon}_{i}^{0}, \bar{\varepsilon}_{i}^{1}, \bar{\varepsilon}_{i}^{2}\right)\right\}_{i=1}^{N}$ that satisfies

$$
U_{i}\left(\bar{\varepsilon}_{i}^{0}, \bar{\varepsilon}_{i}^{1}, \bar{\varepsilon}_{i}^{2} ; \bar{\varepsilon}_{-i}^{0}, \bar{\varepsilon}_{-i}^{1}, \bar{\varepsilon}_{-i}^{2}, \mathbf{s}^{0}\right) \geq U_{i}\left(\bar{\varepsilon}_{i}^{0 \prime}, \bar{\varepsilon}_{i}^{1 \prime}, \bar{\varepsilon}_{i}^{2 \prime} ; \bar{\varepsilon}_{-i}^{0}, \bar{\varepsilon}_{-i}^{1}, \bar{\varepsilon}_{-i}^{2}, \mathbf{s}^{0}\right)
$$


Figure 8: Preemption incentive

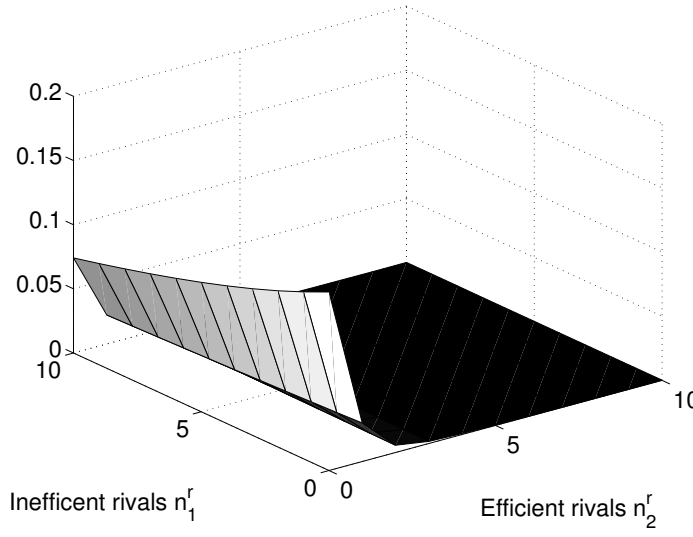

(a) Expected number of competitors

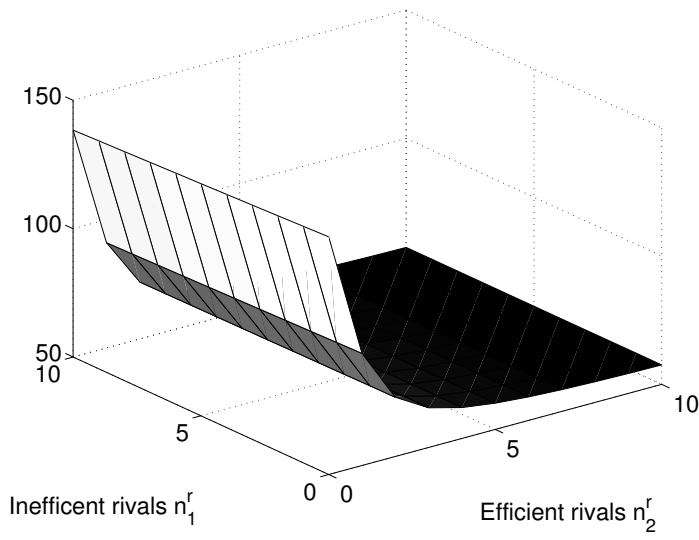

(b) Ex-ante value function

Figure 9: War of attrition incentive

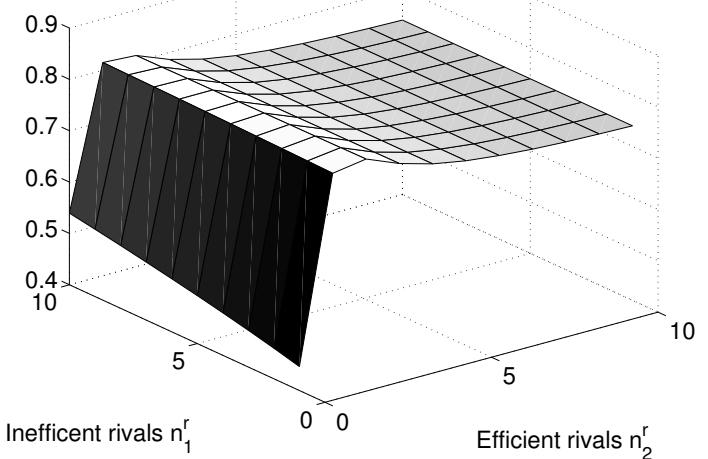

(a) Expected number of competitors

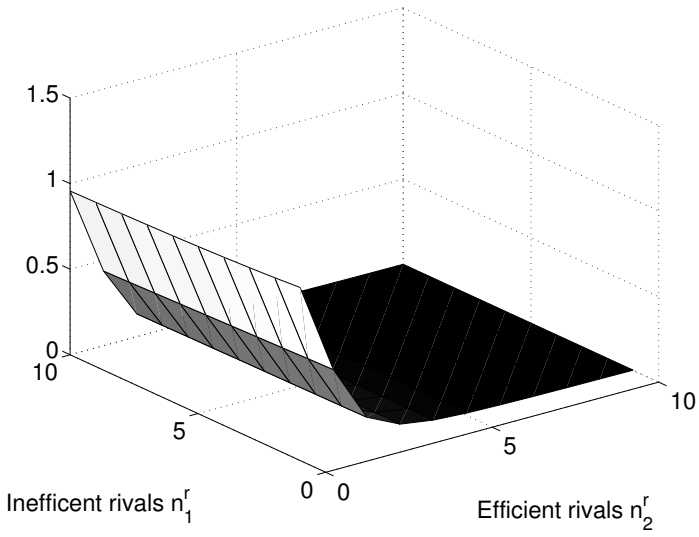

(b) Ex-ante value function 
Table 4: Choice probabilities, MPE vs. OLE

\begin{tabular}{|c|c|c|c|c|c|c|}
\hline \multirow{3}{*}{$\begin{array}{l}\text { Rivals' state } \\
\qquad\left(n_{1}^{r}, n_{2}^{r}\right)\end{array}$} & \multicolumn{6}{|c|}{ Own state } \\
\hline & \multicolumn{2}{|c|}{$s_{i}=0$} & \multicolumn{2}{|c|}{$s_{i}=1$} & \multicolumn{2}{|c|}{$s_{i}=2$} \\
\hline & MPE & OLE & MPE & OLE & MPE & OLE \\
\hline$(0,0)$ & 0.4234 & & 0.9955 & & 0.9999 & \\
\hline$(0,1)$ & 0.4186 & & 0.9954 & & 0.9999 & \\
\hline$(0,2)$ & 0.4139 & & 0.9953 & & 0.9999 & \\
\hline$(0,3)$ & 0.4094 & & 0.9952 & & 0.9999 & \\
\hline$(1,0)$ & 0.1182 & & 0.9519 & & 0.9999 & \\
\hline$(1,1)$ & 0.1171 & 03600 & 0.9513 & 09946 & 0.9999 & 00963 \\
\hline$(1,2)$ & 0.1161 & & 0.9507 & & 0.9999 & \\
\hline$(1,3)$ & 0.1150 & & 0.9500 & & 0.9999 & \\
\hline$(2,0)$ & 0.0615 & & 0.8831 & & 0.9999 & \\
\hline$(2,1)$ & 0.0613 & & 0.8826 & & 0.9999 & \\
\hline$(2,2)$ & 0.0611 & & 0.8822 & & 0.9999 & \\
\hline$(2,3)$ & 0.0609 & & 0.8817 & & 0.9999 & \\
\hline
\end{tabular}

for all $\left(\bar{\varepsilon}_{i}^{0 \prime}, \bar{\varepsilon}_{i}^{1 \prime}, \bar{\varepsilon}_{i}^{2 \prime}\right) \in \mathbb{R}^{3}$ and for $i=1, \ldots, N$.

We solve for the equilibrium numerically to obtain the corresponding choice probabilities (see Table 4). As can be seen, firms enter with a lower probability than in the MPE, but once in the industry, they are committed to stay in with almost probability one. The probability barely increases when moving from the inefficient state $s_{i}=1$ to the efficient state $s_{i}=2$.

To illustrate the role of dynamic strategic interaction in the MPE relative to the OLE, where dynamic strategic interaction is absent, we compare the average life cycle of the penicillin industry based on 200 simulated sample paths under the two equilibrium concepts in Figure 10. The top panel shows the early years of the industry and that more firms enter early in an MPE to preempt their rivals. Further entry is successfully discouraged. Consequently, the industry reaches its peak earlier. In the OLE, entry cannot be discouraged, hence the industry grows at a lower rate, but eventually more firms enter. More importantly, firms cannot react to rivals becoming efficient. It is this possibility to adapt strategies to rivals' actions over the whole life cycle of the industry, i.e., the dynamics in the strategic interaction, that triggers the shakeout. Consequently, open-loop dynamics do not involve a shakeout.

To further illustrate the dynamics of strategic interaction, for a given industry state we plot the mean and variance of the number of firms in the following period in Figures 
Figure 10: Average number of firms over time, MPE vs OLE
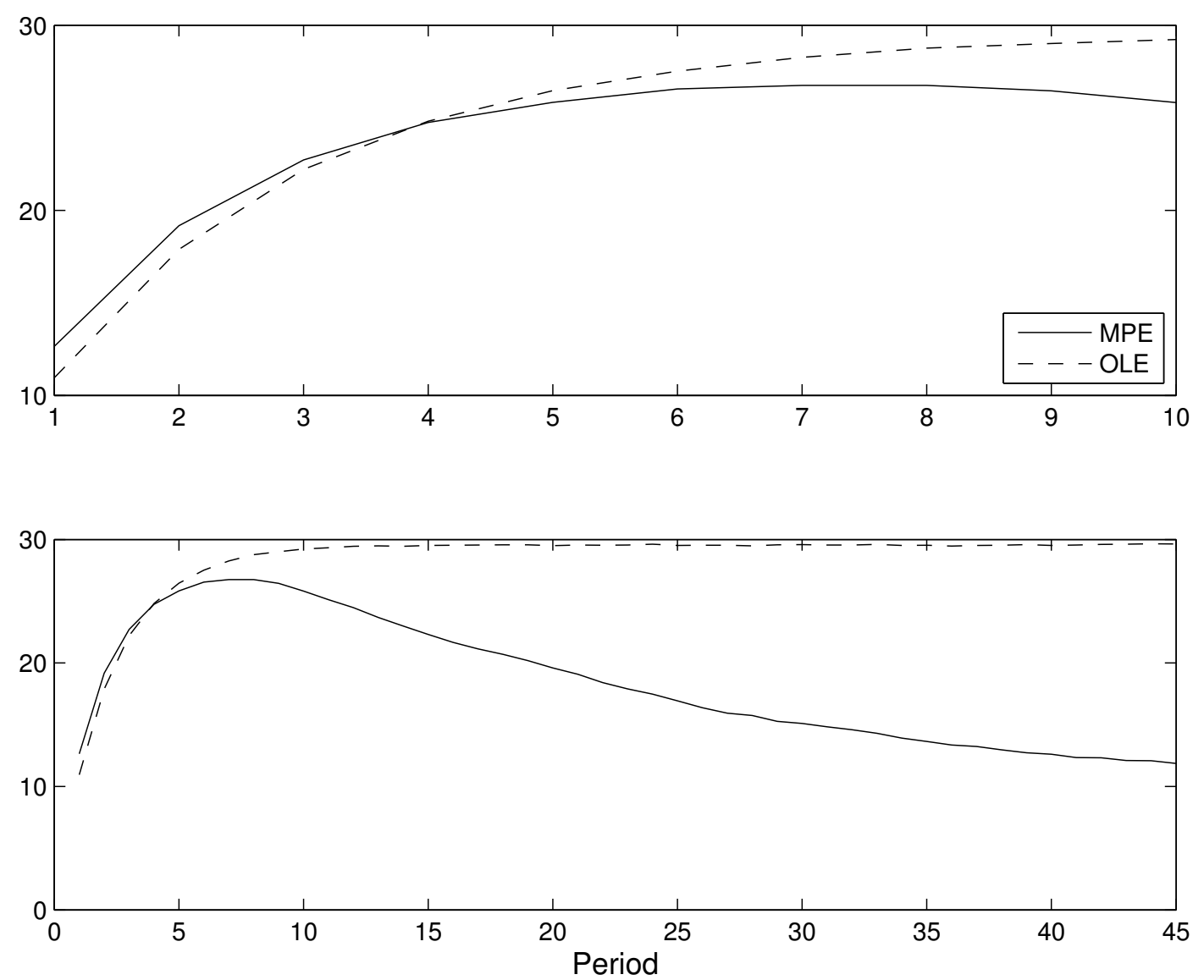

Notes: The top panel shows a zoom into the upper-left corner of the bottom panel. 
Figure 11: Mean of the number of firms

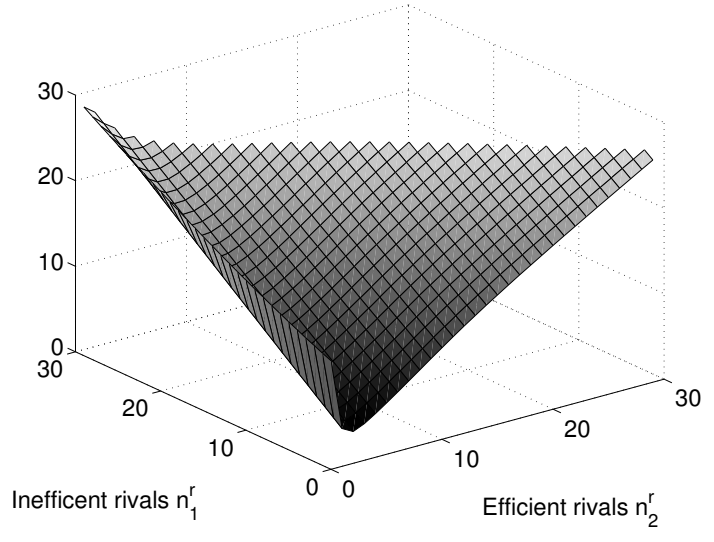

(a) MPE

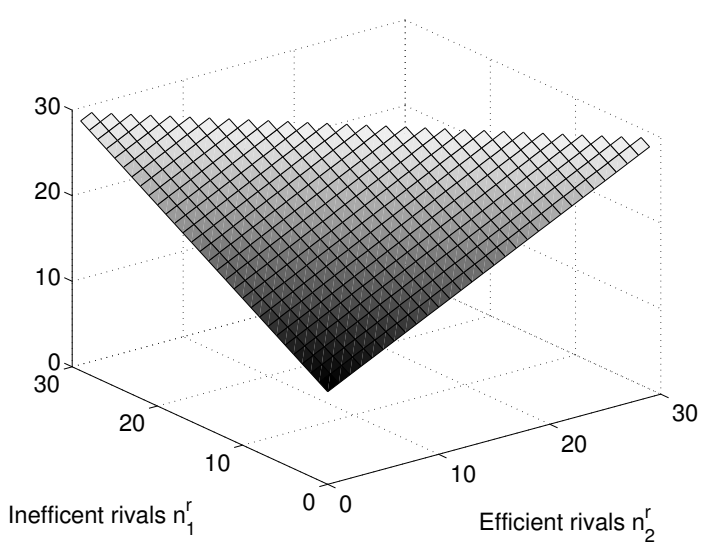

(b) OLE

11 and 12 in the two different equilibria. Figure 11 shows the expected number of incumbents firms in the next period given that the current state of the industry is given by the number of efficient and inefficient firms on the bottom axes. The left panel shows that there is again a non-monotonicity in the number of efficient firms. First, an increase in the number of efficient firms discourages further entry and encourages exit by inefficient firms, reducing the expected number of expected incumbents next period. As the number of efficient firms increases beyond two, the increased probability of survival of an efficient firm outweighs the lower probability of survival of an inefficient firms. The right panel shows the expected number of incumbents in the OLE. The expected number of firms is not only monotonically increasing in the number of current incumbents, but also increasing linearly everywhere. The reason is that strategies only depend on firm's own states and not on other firms' states (for example the number of efficient firms).

Figure 12 plots the variance of the number of next period incumbents as a function of the current state. Again, the MPE exhibits non-monotonicity with the variance lowest at the long run average of efficient firms, whereas for the OLE, variance is decreasing in the number of incumbents in a linear monotone fashion.

\section{Conclusion}

The paper demonstrates how the frequently observed industry life cycle pattern of a massive entry wave followed by a shakeout can be rationalized within a parsimonious dynamic oligopoly similar in spirit to models developed by Ericson and Pakes (1995) and subsequent authors. Substantial potential gains of operating at the industry's technolog- 
Figure 12: Variance of the number of firms

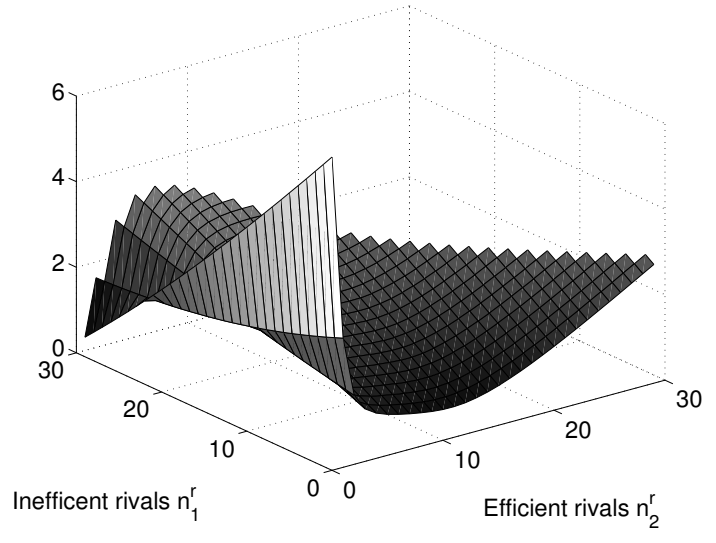

(a) MPE

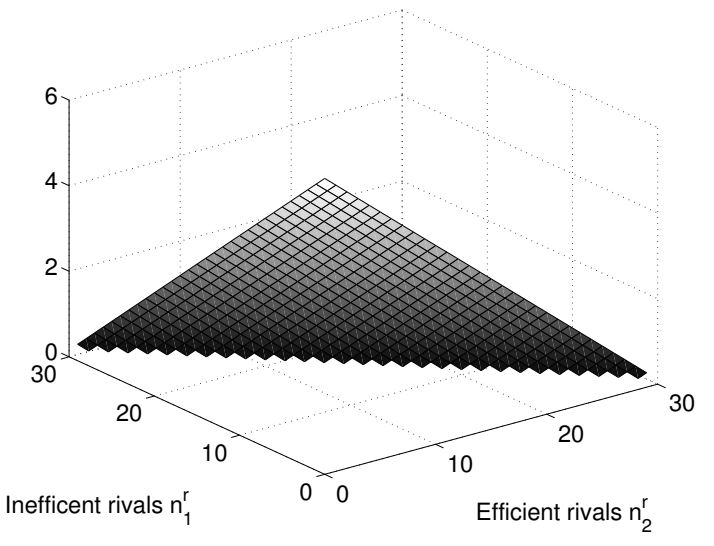

(b) OLE

ical frontier gives entrepreneurs incentives to enter a new industry as early as possible. With the first adopters of highly innovative technology becoming dominant in the market, prospects of unsuccessful firms diminish quickly, causing them to exit the market gradually.

The model presented is close to Jovanovic and MacDonald (1994) but allows for strategic interaction. We have shown that substantial strategic effects are present by calibrating the model to the life cycle of the U.S. postwar penicillin industry. In particular, we showed that prior to successful innovation preemption incentives are present, accelerating early entry in the industry. After only a few incumbents have successfully innovated, firms are more concerned with outlasting their competitor incumbents, which is characteristic of a war of attrition. We show that dynamic strategic interaction is instrumental in generating the typical life cycle of an industry. When restricting firms to open-loop strategies, entry is less rapid and the number of incumbents settles at a high level with shakeouts not occuring.

\section{References}

Backus, M. P., And J. F. Stauffer (1955): "The production and selection of a family of strains in Penicillium chrysogenum," Mycologia, 47, 275-428.

Barreiro, C., J. F. Martin, and C. Garcia-Estrada (2012): "Proteomics Shows New Faces for the Old Penicillin Producer Penicillium chrosgenum," Journal of Biomedicine and Biotechnology, pp. 1-15.

Besanko, D., U. Doraszelski, Y. Kryukov, and M. Satterthwaite (2010): 
"Learning-by-doing, Organizational Forgetting, and Industry Dynamics:," Econometrica, 78(2), 453-508.

CABral, L. (1993): "Experience advantages and entry dynamics," Journal of Economic Theory, 59(2), 403-416.

Cabral, L. (2011): "Technology uncertainty, sunk costs, and industry shakeout," Industrial and Corporate Change, pp. 1-14.

Calam, C. T. (1987): Process Developments in Antibiotic Fermentations. Cambridge University Press, Cambridge.

Dixit, A., And C. Shapiro (1986): "Entry Dynamics with Mixed Strategies," The Economics of Strategic Planning: Essays in Honor of Joel Dean, Lexington Mass.: Lexington Books. Edited by Lacy Glenn Thomas III.

Doraszelski, U., And M. Satterthwaite (2010): "Computable Markov-perfect industry dynamics," The RAND Journal of Economics, 41(2), 215-243.

Ericson, R., And A. PAkes (1995): "Markov-Perfect Industry Dynamics: A Framework for Empirical Work," The Review of Economic Studies, 62(1), 53-82.

Federal Trade Commission (1958): Economic Report on Antibiotics Manufacture. US Government Printing Office.

Fudenberg, D., and J. Tirole (1985): "Preemption and Rent Equalization in the Adoption of New Technology," The Review of Economic Studies, 52(3), 383-401.

Gowrisankaran, G. (1999): "Efficient Representation of State Spaces for Some Dynamic Models," Journal of Economic Dynamics and Control, 23, 1077-1098.

Hopenhayn, H. (1993): "The shakeout," Economics Working Paper No. 33, Universitat Pompeu Fabra.

Horvath, M., F. Schivardi, and M. Woywode (2001): "On industry life-cycles: delay, entry, and shakeout in beer brewing," International Journal of Industrial Organization, 19, 1023-1052.

Humphrey, J. H., M. V. Mussett, and W. L. M. Perry (1952): "The second international standard for penicillin," Bulletin of the World Health Organization, 9, $15-28$.

Igami, M., And N. YAng (2014): "Cannibalization and Preemptive Entry in Heterogeneous Markets," Working Paper, Yale University.

Jovanovic, B., and G. M. MacDonald (1994): "The Life Cycle of a Competitive Industry," Journal of Political Economy, 102(2), 322-347. 
KLePper, S. (1996): "Entry, Exit, Growth, and Innovation over the Product Life Cycle," The American Economic Review, 86(3), 562-583.

Klepper, S., And K. L. Simons (1997): "Technological Extinctions of Industrial Firms: An Inquiry into their Nature and Causes," Industrial and Corporate Change, $6(2), 379-460$.

(2005): "Industry shakeouts and technological change," International Journal of Industrial Organization, 23, 23-43.

Maskin, E., And J. Tirole (1994): "Markov perfect equilibrium," Discussion Paper - Harvard Institute of Economic Research.

(2001): "Markov Perfect Equilibrium: I. Observable Actions," Journal of Economic Theory, 100, 191-219.

Neushul, P. (1993): "Science, Government, and the Mass Production of Penicillin," Journal of the History of Medicine and Allied Sciences, 48, 371-395.

PAkes, A., And P. MCGuire (1994): "Computing Markov-Perfect Nash Equilibria: Numerical Implications of a Dynamic Differentiated Product Model," The RAND Journal of Economics, 25(4), 555-589.

Pesendorfer, M., and P. Schmidt-Dengler (2008): "Asymptotic Least Squares Estimators for Dynamic Games," The Review of Economic Studies, 75, 901-928.

RAPER, K. B. (1946): "The development of improved penicillin producing molds," Annals of the New York Academy of Sciences, 48, 41-56.

Rust, J. P. (1994): "Structural Estimation of Markov Decision Processes," Handbook of Econometrics, 4, 3082-3139.

Suarez, F. F., And J. M. Utterback (1995): "Dominant Designs and the Survival of Firms," Strategic Management Journal, 16(6), 415-430.

Tornqvist, E. G. M., And W. H. Peterson (1956): "Penicillin Production by High-Yielding Strains of Penicillium chrysogenum," Applied Microbiology, 4(5), 277283.

Utterback, J. M., And F. F. SuArez (1993): "Innovation, competition, and industry structure," Research Policy, 22, 1-21.

Wooldridge, J. M. (1995): "Score diagnostics for linear models estimated by two stage least squares," Advances in Econometrics and Quantitative Economics: Essays in Honor of Professor C. R. Rao, ed. G. S. Maddala, P. C. B. Phillips, and T. N. Srinivasan, pp. 66-87. 


\section{A. The development of high-yielding penicillin strains}

The development of high-yielding strains of the Penecillium mold had a substantial impact on the production process. At the time of its discovery, Alexander Fleming's original strain produced about 2 international units (see footnote 9) per milliliter (or 1.2 $\mu \mathrm{g} / \mathrm{ml}$ ) of production broth (Barreiro, Martin, and Garcia-Estrada, 2012). Raper (1946) describes the efforts that were made to improve this proportion. Penicillin strains were often subject to considerable variation in laboratory cultures and thereby, substrains could be separated that possessed higher productivity. This method is known as artificial selection or selective breeding in life sciences.

In order to accelerate this process, the NRRL, with the help of the U.S. army, conducted a worldwide search for penicillin strains (Neushul, 1993). Samples of mold were collected in different places of the world in the hope to find more productive natural variants. The fact that the by far most promising strain, Penicillium chrysogenum NRRL 1951 (realizing yields of $100 \mathrm{IU} / \mathrm{ml}$ ), was found on a moldy cantaloupe at a market in Illinois in 1943, became anecdotal. This strain showed a very high variability and thus was the parent to many superior producing strains (Raper, 1946, Figure 1). One of the earliest descendant, strain NRRL 1551-B25, was especially suitable for submerged growth (Raper, 1946, p. 43) and reached yields up to $250 \mathrm{IU} / \mathrm{ml}$ (Backus and Stauffer, 1955, p. 431).

Another step to improve yields was to induce mutation by ultraviolet and X-ray radiation. In 1944, at the Carnegie Institution's Cold Spring Harbor Laboratory in a joint effort with the NRRL, mutant X-1612 was developed (Raper, 1946). With yields of 500-600 IU/ml it was referred to as the first "super-strain". Another mutant of this strain, the Wis Q-176 (900 IU/ml), created by ultraviolet irradiation at the University of Wisconsin in 1945, started the successful Wisconsin family of superior strains (Barreiro, Martin, and Garcia-Estrada, 2012).

At that time, the penicillin strains employed in the production process naturally produced yellow pigments that had to be extracted to obtain the pure pharmaceutical substance. This procedure was usually accompanied with losses. Backus and Stauffer (1955) describe in detail that by the time of 1947, pigmentless strains were encountered at Wisconsin. Although the pigmentless BL3-D10 had a 25\% disadvantage in yield compared to Q-176, it proved to be a very favorable breeding stock. Soon, the pigmentless family could outperform previous strains (some members accomplished yields up to 
$3000 \mathrm{IU} / \mathrm{ml}$ ) and Wisconsin's 54-1255 became the laboratory reference strain (Barreiro, Martin, and Garcia-Estrada, 2012, p. 3).

In addition to the important advances funded by public sources, research and development was slowly taken up by the private sector. Unfortunately, only few data are available about the strain improvement programs of private companies (Barreiro, Martin, and Garcia-Estrada, 2012). For the time of 1950 and later, we refer to Calam (1987) who depicts yield rates doubling every 6 to 7 years. Current industrial strains exhibit yields of more than 65 gram per liter of production medium $(108355 \mathrm{IU} / \mathrm{ml})$. This spectacular shift in the extensive margin of production transformed a once unaffordable drug, exclusively produced for military purposes, to a mass product readily available to everybody. 